Portland State University

PDXScholar

Fall 11-13-2017

\title{
Supervisor Mindfulness and Its Association with Leader-Member Exchange
}

Dana Anuhea Auten

Portland State University

Follow this and additional works at: https://pdxscholar.library.pdx.edu/open_access_etds

Part of the Psychology Commons

Let us know how access to this document benefits you.

\section{Recommended Citation}

Auten, Dana Anuhea, "Supervisor Mindfulness and Its Association with Leader-Member Exchange" (2017). Dissertations and Theses. Paper 4061.

https://doi.org/10.15760/etd.5945

This Thesis is brought to you for free and open access. It has been accepted for inclusion in Dissertations and Theses by an authorized administrator of PDXScholar. Please contact us if we can make this document more accessible: pdxscholar@pdx.edu. 
Supervisor Mindfulness and Its Association with Leader-Member Exchange

by

Dana Anuhea Auten

A thesis submitted in partial fulfillment of the requirements for the degree of

\author{
Master of Science \\ in \\ Psychology
}

Thesis Committee:

Charlotte Fritz, Chair

Todd Bodner

Jennifer Dimoff

Portland State University

2017 
(C) 2017 Dana Anuhea Auten 


\begin{abstract}
Mindfulness has recently gained attention within work contexts. Mindfulness training interventions (e.g., mindfulness-based stress reduction; MBSR) are commonly implemented for employees within organizations. Mindfulness has been associated with multiple employee performance, relational, and well-being outcomes. Although mindfulness has become a popular practice within organizations, empirical research falls behind and has not explored many potential research avenues. As leaders play influential roles within organizations, mindfulness may influence leader behaviors, to an extent that leader mindfulness affects employees. This study examined the relationship between supervisor mindfulness and leader-member exchange (LMX), which entails quality of mutual support, trust, and respect within supervisor-subordinate relationships. In addition, the proposed study sought to empirically support proposed theoretical frameworks by examining affective, cognitive, and behavioral mechanisms of empathic concern, perspective taking, and response flexibility, as mediators in the supervisor mindfulness-LMX relationship. Supervisor workload was also examined as a moderator to assess conditions under which the supervisor mindfulness-LMX relationship exists. A sample of 202 individuals who currently supervise employees was collected using the online survey platform, Amazon's Mechanical Turk. Two approaches towards mediation provided support for the mediating roles of empathic concern and response flexibility in the relationship between supervisor mindfulness and LMX. Theoretical and practical contributions, as well as limitations and future directions are discussed.
\end{abstract}


Keywords: Mindfulness, empathic concern, perspective taking, response flexibility, leadership, leader-member exchange 


\section{Table of Contents}

Abstract............................................................ i

List of Tables......................................................... iv

List of Figures......................................................

Introduction.......................................................... 1

Mindfulness at Work...................................................... 5

Mindfulness and Leadership.......................................... 10

Leader-Member Exchange...................................... 11

Hypothesis Development........................................... 15

Supervisor Mindfulness and Affect, Cognition, and Behavior............. 15

Supervisor Affect, Cognition, and Behavior and Leader-Member Exchange 22

Supervisor Mindfulness and Leader-Member Exchange................... 25

Workload as a Moderator............................................... 28

Method........................................................... 31

Results......................................................... 37

Additional Analyses........................................... 45

Discussion........................................................... 47

Contributions.................................................. 47

Limitations and Implications for Future Research.................... 50

Practical Implications........................................... 55

Tables........................................................... 59

Figures............................................................. 62

References............................................................ 68

Appendices........................................................ 84

A. Survey Measures and Response Scales........................... 84

B. Attention Check Items....................................... 87 


\section{List of Tables}

Table 1: Descriptive Statistics, Zero-order Correlations, and Cronbach's Alphas for Study Variables..................................................... 59

Table 2: Direct and Indirect Effects of the Hypothesized Mediation Model........ 60

Table 3: Interaction Effect of Mindfulness and Workload in Predicting Response

Flexibility ........................................................... 61 


\section{List of Figures}

Figure 1: Hypothesized Moderated Mediation Model........................ 62

Figure 2: Statistical Model with Beta Coefficients for Parallel Mediation.......... 63

Figure 3: Piecemeal Mediation Results with Empathic Concern................. 64

Figure 4: Piecemeal Mediation Results with Perspective Taking................. 65

Figure 5: Piecemeal Mediation Results with Response Flexibility............... 66

Figure 6: Interaction Effect of Mindfulness and Workload in Predicting Response

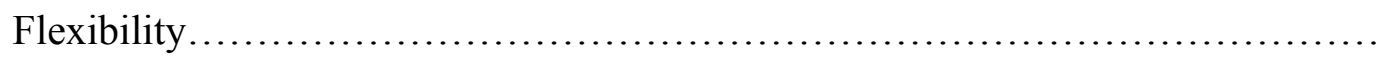




\section{Introduction}

Leadership is an important determinant of the employee health, well-being, and performance (Gilbreath \& Benson, 2004; Kelloway \& Barling, 2010; Martin, Guillaume, Thomas, Lee, \& Epitropaki, 2016). Quality of leadership has been linked to essentially every health outcome for employees (e.g., psychological well-being, organizational safety; Kelloway \& Barling, 2010; Mullen \& Kelloway, 2011) and predicts many indicators of organizational performance, such as organizational commitment and turnover (Dulebohn, Bommer, Liden, Brouer, \& Ferris, 2012). Meta-analytic findings indicate that despite the direct contributions of leader behaviors to organizational outcomes, it is in fact the nature of relationships between leaders and their employees that explains this association (Dulebohn et al., 2012). It is thus essential to determine processes through which high-quality supervisor-subordinate relationships are developed and sustained.

Being more mindful (i.e., being non-judgmentally attentive and aware in the present moment) has beneficial outcomes for workers. Broadly speaking, mindfulness has been linked to improvements in employee performance, relationships, and well-being (Glomb, Duffy, Bono \& Yang, 2011; Good et al., 2016). While there is evidence that practicing mindfulness has implications for the individual, there is a limited understanding of the extent to which mindful individuals affect others. Although some researchers argue that mindfulness manifests at multiple levels (i.e., employee, supervisor, organizational; Hülsheger, 2015; Sutcliffe, Vogus, \& Dane, 2016), most research examines mindfulness at the employee level. Considering the influential role 
that leaders play in employee performance and well-being (Kelloway \& Barling, 2010; Skakon, Nielsen, Borg, \& Guzman, 2010) and the inherently interpersonal aspects of mindfulness, I seek to examine mindfulness at the leader level and its potential effects on supervisor-subordinate relationship quality.

Associations between mindfulness and leadership outcomes of mindfulness like leader-member exchange (LMX), transformational leadership, and supervisor support, have not been explored in depth. Additionally, mindfulness interventions tend to focus on individual employee outcomes. Mindfulness based stress reduction (MBSR) programs (Kabat-Zinn, 1982) are commonly utilized in clinical populations because of their success in managing chronic pain, stress, and disorders. These interventions are becoming common in non-clinical populations, such as workplaces, as positive outcomes have been observed within these settings as well (Bishop et al., 2004; Shapiro et al., 2005). MBSR is incredibly beneficial, but is most commonly implemented at the individual or employee level and for the purpose of benefiting health, well-being, and performance. Practitioners continue to intervene at the employee level despite initial research that has shown supervisor and organizational mindfulness (e.g., collective mindfulness; see Sutcliffe et al., 2016) may positively impact employees. It is likely that implementing this training at a higher level (i.e., for supervisors) could establish positive effects of supervisor mindfulness on supervisor-subordinate relationships (Hülsheger, 2015), in addition to employee performance and well-being.

The nature of the relationship between supervisor mindfulness and leadership is important to address as we know how integral and influential the role of a leader is to 
organizations and employees (Bono \& Yoon, 2012). I focus on mindfulness in leaders, and specifically how supervisor mindfulness relates to interpersonal leader behaviors. Therefore, the purpose of this Master's thesis is to better explain how supervisor mindfulness relates to interpersonal leader behavior. I examine the link between supervisor mindfulness and leader-member exchange (LMX; i.e., the quality of mutual trust, respect, and support in supervisor subordinate relationships). If researchers do not understand how mindfulness manifests at specific levels (e.g., supervisor level), then we cannot understand how it is transferred from one organizational level to another (e.g., from leader to subordinate).

Glomb and colleagues (2011) proposed a process framework of mindfulness, which serves as the primary support for the arguments made in this proposal. They argue mindfulness occurs through three core processes that serve to enhance self-regulation of thoughts, emotions, and behaviors, thereby improving employee performance, wellbeing, and relationships via several secondary processes. Existing research suggests that mindfulness impacts relationships specifically through the secondary processes of empathy and response flexibility. I therefore explore empathic concern (i.e., affective empathy), perspective taking (i.e., cognitive empathy), along with response flexibility, as potential mechanisms through which leader mindfulness relates to LMX. This contributes to the theoretical understanding of how mindfulness impacts work outcomes, and provides insight on how mindfulness functions interpersonally within organizations.

This research contributes to the literature in four ways. First, this study explores the associations between mindfulness and specific leader behaviors. Second, to explore 
the supervisor mindfulness and behavior, I utilize a framework that involves three mediating mechanisms: empathic concern (i.e., affective empathy or feelings of warmth or compassion for others), perspective taking (i.e., cognitive empathy or the attempt to see others' points of view), and response flexibility (i.e., the ability to pause before taking action). Examining these mechanisms may lend support to the cognitive, affective, and behavioral processes of mindfulness. Third, this research model also explores potential moderating factors. Specifically, I test workload (i.e., the volume of work an employee has to complete; Spector \& Jex, 1998) as a moderator of the conditional indirect effects of mindfulness on LMX, thus providing insight into work conditions that enable or disable the positive outcomes of mindfulness. Finally, the findings of this study may inform future organizational interventions. Support for the proposed hypotheses may provide initial direction for organizations to consider employing mindfulness interventions with the goal of improving LMX. This would benefit employees and organizations as higher levels of LMX are related to improved job satisfaction, organizational commitment, and citizenship behaviors, along with decreased turnover intentions (Dulebohn et al., 2012), work family conflict (Culbertson, Huffman, \& AldenAnderson, 2009), and burnout (Huang, Chan, Lam, \& Nan, 2010). Furthermore, while LMX has been associated with a number of positive outcomes, its antecedents receive less attention. As such, this may present a novel training to increase levels of LMX. Additionally, mindfulness interventions could potentially improve outcomes above and beyond leadership, as it is strongly associated with the improvement of psychological and physical health and well-being (Brown \& Ryan, 2003). 


\section{Mindfulness at Work}

Mindfulness is traditionally observed as a Buddhist practice, where those who participate seek a state of full attentiveness and awareness during their moment-tomoment experiences (Kabat-Zinn, 1990; Bishop et al., 2004). As mindfulness has been adopted by Western cultures, its conceptualization, operationalization, and implications have expanded. It is now commonly explained as being a state, stable characteristic, or behavioral pattern where individuals may hold temporary mindful states from one moment to another, but can also have a stable mindful inclination (Brown \& Ryan, 2003), or tendencies to intentionally behave mindfully. Some have derived it directly from its roots, describing it as a level of increased attention and awareness to the present moment (Bishop et al., 2004; Brown \& Ryan, 2003). Others have viewed it as a process during which individuals are decoupled from experiences and emotions, observe them objectively, and reduce mental and emotional reactivity (Glomb et al., 2011; Baer, Smith, \& Allen, 2004). Despite various explanations, the construct of mindfulness encompasses all of these frameworks and lenses - they are all interrelated and the quality of one definition does not exceed another (Quaglia, Braun, Freeman, McDaniel, \& Brown, 2016). As such, regardless of conceptualization, and though there are still concerns with its development, mindfulness continues to be used as a convenient and novel tool for organizations and employees (Hülsheger, 2015). For the purpose of this study, I refer to mindfulness as a behavioral pattern in which supervisors tend to act with non-judgmental attention and awareness to the present moment. 
Mindfulness within workplace contexts often comes in the form of employee interventions or trainings, where employees are taught how to practice being mindful. Many of these interventions are modeled after clinical interventions, such as MBSR. As these interventions have been implemented, empirical research evaluating both intervention effects of mindfulness has grown. In order to comprehend the development of mindfulness as a practice used to benefit organizational outcomes, I review recent literature before discussing mindfulness specifically in leaders.

Mindfulness in employees has been linked to health and well-being outcomes. Studies have found relationships between mindfulness and work-family balance, sleep quality, vitality (Allen \& Kiburz, 2012), emotional exhaustion, and need satisfaction (Reb, Narayanan, \& Ho, 2015). Research has additionally found relationships with workspecific outcomes, such as task performance, organizational citizenship behaviors (OCBs), workplace deviance (Dane \& Brummel, 2013; Reb et al., 2015), turnover intentions (Dane \& Brummel, 2013), counterproductive work behaviors (Krishnakumar \& Robinson, 2015), and safety compliance and participation (Zhang \& Wu, 2014). Multiple studies have documented intervention effects, which demonstrate that training mindfulness is effective in creating tendencies to behave mindfully and in altering employee outcomes. MBSR interventions have been shown to reduce perceived stress (Klatt, Buckworth, \& Malarkey, 2009; Shapiro, Astin, Bishop, \& Cordova, 2005; Wolever et al., 2012), burnout (Bazarko, Cate, Azocar, \& Kreitzer, 2013; Roeser et al., 2013), sleep disturbances (Klatt et al., 2009), heart rate variability (Wolever et al., 2012), occupational stress (Roeser et al., 2013), and rumination about work at home (Crain, 
Schonert-Reichl, \& Roeser, 2016; Querstret, Cropley, \& Fife-Schaw, 2016). Furthermore, mindfulness based interventions have demonstrated improvements in general health (Bazarko et al., 2013), sleep quality (Hülsheger, Feinholdt, \& Nübold, 2015; Klatt et al., 2009; Querstret et al., 2016; Wolever et al., 2012), sleep quantity (Crain et al., 2016), satisfaction with work and family life (Crain et al., 2016), work-life balance (Michel, Bosch, \& Rexroth, 2014), and psychological detachment (Hülsheger et al., 2014; Michel et al., 2014).

Intervention studies and randomized control trials demonstrate the viability of mindfulness interventions to increase mindfulness in workers and to improve work behaviors, in addition to psychological and physiological well-being. Mindfulness can be self-taught (Hülsheger et al., 2015), trained in shorter periods of time (Klatt et al., 2009; Michel et al., 2014), trained in various formats, and in various samples (e.g., working adults in general, nurses, and teachers). Mindfulness trainings are effective for employees, but research must reflect on theoretical foundations of mindfulness in order to improve comprehension of the processes of behaving mindfully (i.e., its mechanisms) and how these programs may be best developed to provide the many benefits that have been empirically examined. Furthermore, these mechanisms should be utilized to explain how mindfulness in one extends beyond the individual and impacts other individuals.

As previously mentioned, I use Glomb and colleagues' (2011) mindfulness process framework to support my hypotheses. Their framework explains why and how mindfulness impacts work performance, employee well-being, and relationships at work. Their review of previous mindfulness research converges on one central outcome: 
improved self-regulation of thoughts, emotions, behaviors, and physiological reactions. This conclusion fueled their process framework, which entails three mental and physiological core processes and seven secondary processes of mindfulness that improve the outcomes of performance, well-being, and relationships via improved self-regulation.

The first of the three core processes is decoupling of the self from events, experiences, and mental processes. Mindfulness allows individuals to objectively observe both internal and external stimuli, which creates higher meta-awareness. This renewed awareness allows individuals to develop distance between the self (i.e., ego, self-concept) and one's thoughts, emotions, and experiences. Decoupling has also been explained as "decentering", where one sees his or her own thoughts as events in the mind, rather than accurate representations of reality or self-view (Feldman, Greeson, \& Senville, 2010). The second core process is decreased use of automatic mental processes. Humans have an inherent ability to automatize thinking based on prior experiences, entrenched mental models, and habitual and automatic bodily responses. This automaticity is important for survival purposes in that it allows for quick processing and responses, but unfortunately hinders present moment awareness and control (Bargh, 1994). Mindfulness allows individuals to disengage from automatic thought patterns that are driven by past emotions, experiences, and schemas by improving nonjudgmental awareness of thoughts and experiences. Mindfulness increases range of response options, as they are no longer constrained by automaticity, and allows for conscious responding (Siegel, 2010). The third and final core process of mindfulness is awareness of physiological regulation, which promotes balanced regulation of physiological responses. Similar to the decreased 
automaticity process, mindful awareness of bodily responses (e.g., fight or flight responses) allows for improved and thorough interpretation of messages from the body. Mindfulness coordinates the activation and inhibition systems of the body, which generates calmness, connectivity, and physical well-being (Cozolino, 2006; Siegel, 2010).

The secondary processes of mindfulness follow one or more of the three core processes and represent more distal processes that influence employees' abilities to selfregulate thoughts, behaviors, and emotions at work. Glomb et al. (2011) suggest that two processes, namely, empathy and response flexibility specifically influence relational outcomes at work. They additionally suggest that these processes can be affective, cognitive, and behavioral. As such, I will use empathic concern, perspective taking, and response flexibility (which represent affective, cognitive, and behavioral mechanisms, respectively) as mediators of the proposed relationship between leader mindfulness and LMX. Using this framework, this thesis will contribute to mindfulness literature by providing empirical evidence for the suggested process and mechanisms of mindfulness and how it influences outcomes at work. 


\section{Mindfulness and Leadership}

One study describes a developmental learning methodology that utilizes mindfulness practices to transform leader behavioral tendencies from automatic to conscious. It details three phases that include "expanding awareness to receive mindbody insights," "critical reflection and dialogue around mind-body insights to transform behaviors," and "transforming practice into more attuned and accepting ways of being" (Brendel \& Bennett, 2016). It argues that these processes positively affect decisionmaking, communication, creativity, and conflict management. Other research contends the core of mindfulness in leaders is attention, which allows recognition of one's own perceptions or biases, emotional reactions, and actions needed to address realities more effectively (Hunter \& Chaskalson, 2013). Specifically, becoming more aware of implicit or automated habits helps leaders to react and adapt to stressors appropriately, cultivate empathy, perceive the environment more accurately, and mange reactive emotions.

An empirical study on mindful leaders examined the influence of leader mindfulness on employee well-being and performance (Reb, Narayanan, \& Chaturvedi, 2014). In a sample of 95 supervisor-subordinate dyads, with surveys collected at two time points, Reb and colleagues (2014) found that leader mindfulness was significantly related to employee well-being and performance, such that employees with more mindful leaders experienced less exhaustion, higher work-life balance, improved job performance, and lower deviance. In their second study of 79 supervisor-subordinate dyads, they found the relationships between leader mindfulness and job satisfaction, job performance, in-role performance, and organizational citizenship behaviors (OCBs) were mediated by 
employee psychological need satisfaction. Mindful leaders were attuned to the needs of employees, which resulted in satisfaction of those needs. Another study examined how leader mindfulness impacted their own mental well-being (Roche, Haar, \& Luthans, 2014). Under the pretense that leaders at all levels (i.e., top, middle, junior managers, and entrepreneurs) face unprecedented challenges in the global economy, they argue that some leaders take on these challenges better than others, and that this difference lies in mindfulness. They found at all levels of leadership, mindfulness was negatively associated with anxiety, depression, and negative affect, and that these relationships were mediated by psychological capital (Roche, Haar, \& Luthans, 2014). Taken together, these two studies propose that mindfulness as improved attention and awareness, specifically in leaders, can lead to multiple positive outcomes through various mechanisms.

\section{Leader-Member Exchange}

Fostering high-quality relationships is an important component in developing human well-being and doing so at work is strongly influential on workplace outcomes, such as performance and high organizational functioning. A way in which high quality relationships are defined is through leader-member exchange (LMX) (Graen \& Uhl-Bien, 1995). Rooted in social exchange theory, LMX focuses on dyadic relationships between leaders and their employees. Relationships can be classified from low to high quality LMX, where low LMX is characterized by an economic exchange between the employee and supervisor. A low LMX relationship is based on formally agreed upon expectations of reciprocation, whereas a high LMX relationship is warmer and social. Social exchange theory (Blau, 1964; Homans, 1958) posits that leaders who have a high exchange 
relationship with an employee will expect the employee to reciprocate and vice versa (Harris \& Kacmar, 2006). For this reason, high LMX relationships are expected to result in high levels of trust, respect, and mutual obligation (Graen \& Uhl-Bien, 1995).

Examining supervisor-subordinate relationship quality and LMX is important, especially as relationships with one's supervisor are particularly influential. Supervisors have great influence over the nature, beliefs, and norms of the supervisor-subordinate relationship (Bono \& Yoon, 2012; Ashforth, 2001). Poor supervisory relationships are the number one reason for employees quitting their jobs (Buckingham \& Coffman, 1999) and have been associated with negative psychological and physical outcomes. Conversely, positive working relationships with supervisors reduces stress, helps employees cope with stress, and increases employee affective well-being (Skakon et al., 2010).

High quality supervisor-subordinate relationships are characterized by trust, shared goals, mutual caring and concern, loyalty, commitment, and support (Colbert, Bono, \& Puranova, 2008; Cropanzano \& Mitchell, 2005). Due to the shared positive attitudes and behaviors in high LMX relationships, LMX is connected to a host of positive outcomes, such as improved job satisfaction, satisfaction with supervisors, organizational commitment, and citizenship behaviors, along with decreased turnover intentions (Dulebohn et al., 2012). It is also related to stress outcomes, such as decreased work family conflict (Culbertson et al., 2009), burnout (Huang et al., 2010), and emotional exhaustion (Thomas \& Lankau, 2009). Findings from a meta-analysis conducted by Dulebohn and colleagues (2012) confirmed findings from two previous meta-analyses (Gerstner \& Day, 1997; Ilies, Nahrghang, \& Morgeson, 2007), 
demonstrating beneficial outcomes of LMX. They confirm high quality LMX is related to improved perceptual outcomes of justice and empowerment, and attitudinal outcomes of affective, normative, and overall organizational commitment and satisfaction with supervisor, pay, and general job satisfaction. They confirm behavioral outcomes of improved organizational citizenship behaviors and job performance, and reduced turnover intentions and actual turnover. Finally, they confirm high quality LMX is related to reduced role ambiguity and role conflict. This research demonstrates that high quality relationships between supervisors and employees are highly impactful towards employee outcomes (Dulebohn et al., 2012). They show leader characteristics are predictive of employee outcomes via increased LMX, emphasizing the importance of leaders' roles in developing relationships conducive to positive employee and organizational outcomes. Ultimately, researchers have found that high quality exchange relationships are linked to employee thriving and flourishing, as well as that of the organization (Dulebohn et al., 2012). These resource rich relationships create a positive feedback loop in which new resources are generated and re-generated through increased energy, cooperation, and giving (Rousseau \& Ling, 2007). High quality relationships allow for efficient use of resources via improved energy and cooperation. Mutual learning and growth fosters vitality, increases sense of worth, and creates closer relationships (Fletcher, 2007). With individuals fostering and seeking more resource rich and high quality relationships, the social dynamic between supervisors and subordinates becomes generative (Colbert et al., 2008). Thus, it is posited that positive relationships create resources, foster generalized reciprocity, and finally aid in the human need to belong (Bono \& Yoon, 2012). This study 
examines mindfulness as an antecedent of LMX, hypothesizing supervisor mindfulness is related to a higher tendency to show empathic concern, perspective taking, and response flexibility, and that these tendencies are related to improvements in LMX. 


\section{Hypothesis Development}

\section{Supervisor Mindfulness and Affect, Cognition, and Behavior}

Empathy is an interpersonal skill that enables one to recognize and comprehend emotions in another. It allows one to react to and share the emotional states of another (Bakker, Shimazu, Demerouti, Shimada, \& Kawakami, 2011; Davis, 1983). In the development of empathy as a construct, four facets were distinguished: empathic concern, personal distress, perspective taking, and fantasy. For the purposes of this study, I will focus on empathic concern (affective empathy) and perspective taking (cognitive empathy), as they are the two practical and positive aspects of empathy. Since mindfulness has been present in the psychological literature, research has suggested its positive relationship with empathy. Kabat-Zinn (1993), who developed an eight-week mindfulness-based stress reduction course (MBSR), which is now a commonly and widely used program in workplaces, found mindfulness predicted attunement, connection, and closeness in relationships. He posited that mindfulness induced receptive attentiveness, promoting the ability and willingness to take interest in one's partner's emotions. Others further discovered mindfulness was positively related to and predictive of openness, relatedness, and interpersonal closeness (Brown \& Ryan, 2003). Researchers have shown that mindfulness serves an interpersonal function and have demonstrated empathy as a resulting process. Multiple researchers have applied mindfulness in marital and/or family therapy and each found that mindfulness improved individuals' capacities for empathy (Atkinson, 2013; Barnes, Brown, Krusemark, Campbell, \& Rogge, 2007; Block-Lerner, Adair, Plumb, Rhatigan, \& Orsillo, 2007; Gambrel \& Keeling, 2010). 
Davis and Oathout (1987), who specifically studied romantic relationships, found that mindfulness resulted in empathy, which in turn improved relationship satisfaction. Two studies in which MBSR training was administered resulted in increased empathy levels and reduced psychological distress (Birnie, Speca, \& Carlson, 2010; Shapiro, Schwartz, \& Bonner, 1998). Mindfulness has been positively related to empathy, however the majority of this research has only been applied to romantic or familial relationships, and has neglected to examine how empathy induced by mindfulness can impact working relationships and leadership.

Glomb et al. (2011) discuss empathy as a secondary process of mindfulness. They argue that mindfulness induces increased empathy via three core processes, and that empathy in turn develops improvements in affective, cognitive, behavioral, and physiological self-regulation. Empathy allows individuals to see life from others' perspectives (Cozolino, 2006; Siegel, 2007). Empathetic individuals consider the "larger social picture" and consider others' best interests and what it is like to be others, all while holding their own perspectives. Empathy is enhanced first by nonjudgmental awareness of one's own internal thoughts. As individuals develop meta-awareness, capacity to understand internal emotional processes increases, thus allowing individuals to better understand the emotional processes of others (Teasdale et al., 2002). Second, being more physiologically aware may also improve empathy. Empathetic reactions require individuals to experience emotions and physiology of others using subcortical data like heart rates and the limbic system (Cozolino, 2006; Glomb et al., 2011). As such, it is likely that being more mindfully aware of one's own physiology will allow one to better 
attune to, and resonate with, the physiology of others, thereby improving empathy.

Finally, by decoupling from (i.e., observing and not reacting to) one's own negative state, it is likely that one will better tolerate his or her own negative states, as well as the states of others. When one is overwhelmed by negativity, his or her ability to attend to and be compassionate towards others is diminished. Thus, decoupling from one's thoughts and experiences, may improve one's capacity to demonstrate more empathy towards others.

These three core processes of mindfulness are likely to enable improved affective, cognitive, and behavioral self-regulation, thus enhancing empathetic reactions. Due to the nature of previous research on mindfulness and empathy, as well as Glomb and colleagues' (2011) process framework of mindfulness within the workplace, I argue that supervisor empathy, namely empathic concern and perspective taking, are affective and cognitive self-regulatory processes resulting from mindfulness that are associated with higher quality LMX relationships between supervisors and their subordinates.

Empathic concern, also regarded as affective empathy, is defined as "respondents' feelings of warmth, compassion, and concern for others undergoing negative experience" (Davis, 1983, p. 6). Empathic concern entails the emotional response individuals have to the experiences of another and is a positive, helpful, and concerned affective response to what is happening to someone else. Though mindfulness has been positively associated with empathy as a whole construct, its relationship with the empathic concern component varies considerably. Multiple researchers found that mindful attention and awareness was significantly associated with the empathic concern portion of the interpersonal reactivity 
index (Beitel, Ferrer, \& Cecero, 2005; Block-Lerner et al., 2007; Gambrel \& Keeling, 2010), which is composed of all four components of empathy (Davis, 1980).

However, other researchers found that mindfulness was associated with perspective taking and personal distress, but not with empathic concern (Birnie et al., 2010). Furthermore, this study allowed for the establishment of causality, while previous studies that demonstrate positive, significant relationships have not. Thus, it is important to further examine this relationship. I argue that supervisor empathic concern is an affective self-regulatory process resulting from mindfulness. Mindfulness, as the general tendency to maintain high levels of attention and awareness to the present moment, will induce empathic concern within supervisors (particularly towards their employees). They will be less judgmental of their own and others' internal states, more physiologically aware of the experience of others, and better able to decouple themselves from negative states, thus making them more tolerant towards their own and others' negative states (Glomb et al., 2011). I hypothesize that supervisors who are more mindful will respond affectively with better self-regulated feelings of warmth, understanding, and concern, and will report higher levels of empathic concern towards their employees.

Hypothesis 1a: Supervisor mindfulness will be positively related to supervisor empathic concern.

Perspective taking is a cognitive empathetic response. Described as a form of cognitive empathy, perspective taking is the "spontaneous attempt to adopt the perspectives of other people and see things from their point of view" (Davis, 1983). This form of empathy is non-emotional and involves the understanding of others' thoughts and 
experiences. Perspective takers tend to demonstrate better social functioning and are more inclined to attend to and be aware of others, allowing them to help more effectively (Davis, 1983). Multiple studies contend that mindfulness is significantly and positively related to the perspective taking component of empathy (Beitel et al., 2005; Block-Lerner et al., 2007; Gambrel \& Keeling, 2010; Wachs \& Cordova, 2007), with one finding improvements in perspective taking after implementing a MBSR training (Birnie et al., 2010). As mindfulness bolsters attention and awareness, thereby improving nonjudgmental awareness, physiological awareness, and objective, decoupled observations of internal and external stimuli, it may enable supervisors to take perspectives of their employees. If one is nonjudgmentally attuned to others, he or she may have increased capacity to understand others' points of view. In addition, with improved physiological awareness of the self and others, they may better comprehend how another is feeling. Furthermore, the ability to decouple oneself from thoughts, emotions, and experiences prevents one from being consumed by negative reactions, thus allowing them to better attend to experiences of others. I hypothesize that supervisors who are more mindful will be higher in perspective taking.

Hypothesis $1 b$ : Supervisor mindfulness will be positively related to supervisor perspective taking.

Three core processes of mindfulness allow for improvements in affective, cognitive, behavioral, and physiological self-regulation (Glomb et al., 2011; Good et al., 2016). As empathic concern and perspective taking represent affective and cognitive selfregulation, respectively, there is additional room to include behavioral self-regulatory 
outcomes of mindfulness. I argue that supervisors will not only demonstrate improved cognitions and affect with higher levels of mindfulness, but mindful self-regulation will also enable improved actions towards employees. Specifically, more mindful supervisors will demonstrate higher levels of response flexibility towards their employees.

Response flexibility is described as a secondary process of mindfulness, defined as "the ability to pause before taking verbal or physical action" (Glomb et al., 2011, p. 129; Siegel, 2007). This type of behavioral flexibility requires more than just a delay in response; rather, it requires meticulous assessment of present situations, which response options are available in that situation, and finally, an initiation of action. Mindfulness, or non-judgmental attention and awareness, allows individuals via resources to more appropriately reflect upon and react to situations involving others. Cognitive, emotional, and behavioral flexibility is a proposed mechanism of mindfulness, suggesting that mindfulness enables re-perceiving, thus facilitating adaptive, flexible responding to the environment (Shapiro, Carlson, Astin, \& Freedman, 2006). In one study, mindfulness training led to changes in cognitive and behavioral flexibility, which further influenced health outcomes (Carmody, Baer, Lykins, and Olendzki, 2009). It is also argued that the main goal of mindfulness is to increase cognitive and behavioral flexibility in order to allow individuals to adapt to various environments in a meaningful manner (Carson \& Langer, 2006). Researchers who assessed individuals with gambling issues found that those who were more mindful were less prone to problem gambling as they demonstrated more behavioral flexibility, freedom of choice, and less automatic responses to stressors (de Lisle, Dowling, \& Allen, 2012). Another study found that participants in an 
experimental meditation condition showed a reduction in habitual responding, suggesting that those who are more mindful may be better able to respond in non-habitual ways and to find optimal responses to specific situations (Wenk-Sormaz, 2005).

With increased attention and awareness, supervisors are likely provided with a more appropriate array of behavioral responses. Specifically, the improved physiological regulation and awareness that comes with mindfulness allows for a more accurate assessment of environmental stimuli, without acting upon the physiological activation or inhibition that comes with those stimuli (e.g., fight or flight responses). When these automatic reactions occur, it overrides individuals' ability to think and choose reactions (Cozolino, 2006). Therefore, mindful awareness of physiological experiences allows for careful, slow processing of stimuli, thus broadening ways in which individuals might respond. Additionally, decoupling from one's thoughts and experience, in conjunction with viewing experiences non-judgmentally and objectively, allows one to recognize thoughts and reactions towards stimuli not as immediate reality, but rather as occurrences that do not require immediate alteration or response (Chambers et al., 2009). Thus, with increased mindfulness, individuals can better self-regulate behavior by increasing the range and use of response options. Ultimately, mindfulness enables unbiased and accurate assessments of interpersonal processes and social situations (Bishop et al., 2004; Brown \& Ryan, 2007; Glomb et al., 2011). Therefore, I hypothesize that supervisors who are more mindful will exhibit higher response flexibility.

Hypothesis 1c: Supervisor mindfulness will be positively related to supervisor response flexibility towards employees. 


\section{Supervisor Affect, Cognition, and Behavior and Leader-Member Exchange}

I aim to examine how mindfulness may impact LMX quality via its affective, cognitive, and behavioral processes (i.e., empathic concern, perspective taking, response flexibility). It is important to study these mediating mechanisms, as research on supervisor characteristics that influence LMX is limited (Mahsud, Yukl, \& Prussia, 2010). It is also crucial to observe the collective effect that these mediators have on LMX. There is much known about the positive effects of LMX, but its antecedents are lesser known. Thus, evaluating these variables' influences on LMX may provide an avenue to improve LMX in organizational settings.

Interestingly, regardless of its interpersonal nature, the construct of empathy has rarely been related specifically to LMX. In fact, the only empirical research to my knowledge that has examined the relationship between these constructs found that more empathetic leaders displayed more relations-oriented behaviors, which improved subordinate ratings of LMX. Subordinates of leaders who displayed higher levels of empathy rated their relationship quality higher on measures of LMX (Mahsud et al., 2009). Other researchers, though they have not explicitly studied the relationship between empathy and LMX, have stressed the importance of empathy in leadership. While organizations and management do not always view empathy as an important quality in leaders, some argue empathy should in fact be a focal point of leadership (Holt \& Marques, 2012). These researchers found that empathy was considered the least important leadership quality among nine other options and that participants responded this way as they often felt empathy was inappropriate in work settings (Holt \& Marques, 
2012). This is problematic, specifically because although leaders have a duty to care (Ciulla, 2010) and charismatic leaders are notably high in empathy (Schilling, 2010), empathy is largely under-trained in organizations (Karnes, 2009). When leadership is void of emotional intelligence, downward spirals may occur where relationships and organizations become less empathetic and end in employee discontentment (Karnes, 2009). In addition, in environments with higher demands, soft skills like empathy are crucial for organizational functioning (Mill Chalmers, 2010). Upward spiral effects occur with leaders who are willing to create an empowering, vision building climate that results in healthy, high performing employees. It was found later on that when participants were asked what they admired in leaders and what they learned from them, the soft skills like empathy were the qualities and skills that stuck. Participants saw more value in soft skills that their leaders demonstrated (Marques, 2013).

Empathy is an important component of good leadership, but is also extremely influential in relationships. Davis and Oathout (1987) show that various aspects of empathy, including empathic concern and perspective taking, in particular, are crucial for relationship satisfaction between romantic couples. I argue that empathy would play a similar role in supervisor-subordinate relationships. As LMX directly assesses the quality of mutual feelings of trust, liking, support, and respect between supervisors and their subordinates, it is conceptualized in this study as relationship quality between supervisors and subordinates. Empathic concern denotes affective feelings of warmth, compassion, and concern for the pertinent other, and I argue that supervisors who are higher in empathic concern will have higher quality relationships with their employees. They will 
relate better to their employees and demonstrate more concern for them, which would thus improve mutual liking, trust, and respect.

Hypothesis $2 a$ : Supervisor empathic concern will be positively related to leadermember exchange.

Perspective taking is a cognitive form of empathy (Davis, 1980) and reflects an ability to take on perspectives of others and to step outside the self when others are involved. Those with higher perspective taking ability tend to demonstrate better social functioning and are more inclined to attend to and be aware of others, allowing them to help more effectively. This facilitates more rewarding interpersonal relationships (Bakker et al., 2011; Davis, 1983). Additionally, research suggests that empathy in general may allow supervisors to develop relationships with subordinates that are built on mutual trust and cooperation (Mahsud et al., 2009). As such, the perspective taking aspect of empathy should also be positively related to LMX. If a supervisor has more accurate understandings of his or her employees' perspectives, the quality of relationship between the supervisor and employee should benefit. Thus, supervisors who have higher ability to take the perspectives of others will have higher quality ratings of LMX.

Hypothesis $2 b$ : Supervisor perspective taking will be positively related to leadermember exchange.

Response flexibility is the ability to behave in a way that is not automatic, but rather thought through and reflected upon, prior to enacting behavior. It requires a careful assessment of situations, available response options, and initiation of action, and allows individuals to recognize that thoughts and reactions to events are not objective realities 
that need immediate response (Chambers et al., 2009). Response flexibility is thus likely to play an interpersonal role, where improved response flexibility enables better relationship quality or satisfaction. Individuals that respond to others objectively and without immediate reaction may help avoid situations that escalate and dysfunctional forms of communication (Glomb et al., 2011). I contend that supervisors who are higher in response flexibility will experience higher quality LMX, as they will tend to respond to issues with employees in a way that is calmer, more objective, and geared towards problem solving.

Hypothesis 2c: Supervisor response flexibility will be positively related to leadermember exchange.

\section{Supervisor Mindfulness and Leader-Member Exchange}

As previously discussed, leader-member exchange (LMX) is an inherently relational leadership construct. It represents the quality of exchange of trust, respect, and support between supervisors and their subordinates. High LMX represents high levels of reciprocal exchange between a supervisor and employee within a dyad (Graen \& UhlBien, 1995), and has been linked to multiple health, well-being, and performance outcomes (Dulebohn et al., 2012; Gerstner \& Day, 1997; Ilies et al., 2007). Ultimately, LMX represents quality of social exchange between supervisors and subordinates, and I propose that supervisors who are more mindful will have higher quality LMX with their employees. Glomb and colleagues (2011) cite the importance of examining improved social relationships from mindfulness. It is a significant area of research as human thriving stems from positive social connections (Baumeister \& Leary, 1995) and as 
positive workplace relationships can build resources that foster employee thriving, creativity, and organizational citizenship (Dutton \& Heaphy, 2003). In addition social relationships provide a strong buffer to workplace stressors (Cohen \& Wills, 1985). Empathy and response flexibility are highlighted as secondary processes of mindfulness that play critical roles in the development of improved social relationships (Glomb et al., 2011). These two processes are critical components, as they both mark intra-and inter-personal attunement, where awareness of one's own physiological and emotional signals allows for improved sensitivity to others' signals (Siegel, 2007). Those who are more mindful will respond to colleagues with unbiased acceptance and without reacting judgmentally, and will also relate to others in a healthier fashion, where they take others' perspectives without reacting habitually or in a way that enhances negative behavioral escalation (Giluk, 2010).

Leaders who are more mindful will likely have higher quality LMX with their subordinates. Mindfulness allows for decoupling of the self from one's thoughts, emotions, and experiences, which keeps one from reacting to personal negative states, as well as the negative states of others. It also improves physiological awareness and regulation, thereby allowing better physical and emotional attunement with others. Further, mindful non-judgmental awareness of one's own thoughts facilitates empathy for others (Block-Lerner et al., 2007) by increasing meta-awareness and capacity to comprehend both internal and external stimuli. These three core processes of mindfulness lead to improvements in affective self-regulation, which enhances empathic concern towards others. I argue that the affective self-regulation, in the form of empathy, will 
foster higher levels of trust, respect, and support between supervisors and subordinates.

Thus, I hypothesize that empathic concern will partially mediate the relationship between supervisor mindfulness and LMX.

Hypothesis 3a: Supervisor empathic concern will partially mediate the relationship between supervisor mindfulness and LMX.

Further, mindfulness likely fosters higher levels of perspective taking ability.

Supervisors who are more mindful will have increased non-judgmental awareness of both internal and external stimuli, improved physiological regulation, and will be better able to decouple themselves from emotions and experiences, thus improving their cognitive selfregulation and empathetic perspective taking ability. Leaders' increased ability to objectively take perspectives of their subordinates should foster a better understanding of subordinates' experiences, thus increasing trust and respect between supervisors and subordinates. With increased mindful attention and awareness, more mindful supervisors will rate the LMX quality between themselves and employees as higher, due to improved ability to take subordinates' perspectives. As such, perspective taking will partially mediate the relationship between supervisor mindfulness and LMX.

Hypothesis $3 b$ : Supervisor perspective taking will partially mediate the relationship between supervisor mindfulness and LMX.

Furthermore, more mindful supervisors will experience higher quality LMX due to an improvement in response flexibility, which represents behavioral self-regulation capacity. Those who are more mindful are capable of decoupling themselves from experiences and decreasing automaticity in reacting to both internal and external stimuli. 
This allows them to recognize that experiences of what happens within and outside of themselves are not objective reality, but rather subjective experiences that need not be immediately addressed. Additionally, those who are more mindful are more aware of physiological responses to experiences, thoughts, and emotions. As a result, they are better able to regulate automatized physiological responses. Individuals who are higher in mindfulness will be able to respond more flexibly and appropriately to certain situations. In turn, leaders who are more mindful will likely behave in more appropriate ways towards employees. This behavior is likely to foster mutual understanding, trust, respect, and support. I therefore argue that supervisor response flexibility will partially mediate the relationship between supervisor mindfulness and LMX.

Hypothesis 3c: Supervisor response flexibility will partially mediate the relationship between supervisor mindfulness and LMX.

\section{Workload as a Moderator}

Workload is a job stressor that represents the sheer volume of work that is required from an employee and the pace at which an employee is expected to complete his or her work (Spector \& Jex, 1998). Conservation of Resources theory (COR) asserts that individuals seek to acquire and maintain resources, which can be objects, personal characteristics, conditions, or energies. When resources are lost or there is a threat of loss, individuals experience a stress reaction and are thus motivated to preserve and maintain resources (Hobfoll, 1989). Further, according to the Job-Demands Resources theory (Bakker \& Demerouti, 2007), employees must have adequate levels of resources to effectively handle the demands of their jobs. If individuals do not have adequate 
resources, they are at increased risk for experiencing strain. As people have finite levels of resources (Hobfoll, 1989) and workload represents a job stressor or demand, I propose that individuals who are under extremely high levels of workload will consume high levels of resources to cope with the workload. Because individuals must utilize resources to cope with demands, they may not have additional resources available or may be more motivated to protect resources that would originally be used to participate in the processes of mindfulness (i.e., empathic concern, perspective taking, and response flexibility). Thus, I argue that supervisors who are more mindful, but who are under conditions that consume available resources (i.e., high workload), will not have as high quality LMX as those who are more mindful and have higher levels of available resources (i.e., under low workload). I specifically argue that workload will moderate the conditional indirect effects of mindfulness on LMX, such that the relationship between supervisor mindfulness and empathic concern, perspective taking, and response flexibility at work will be weaker under conditions of high workload, thus leading to lower levels of LMX. Mindfulness will not translate into these attitudes and behaviors at work and then into LMX if supervisors do not have the resources available to express mindfulness at work.

Research Question 1a-c: Despite a positive relationship between mindfulness and empathic concern, perspective taking, and response flexibility, supervisors will not have the personal resources to partake in these processes under higher levels of workload. Does workload attenuate the conditional indirect effects of mindfulness on LMX, where more mindful leaders cannot exhibit empathic 
concern, perspective taking, and response flexibility at work under conditions of increased workload, and thus do not demonstrate increased levels of LMX? 


\section{Method}

\section{Participants}

A sample of working supervisors was collected using Amazon's Mechanical Turk (MTurk), which is an online data collection and survey platform that compensates participants for completing tasks that are requested by anonymous others. Studies have found that MTurk provides representative samples, and that these samples are often more diverse than the typical psychological study sample (Buhrmester, Kwang, \& Gosling, 2011). Feitosa, Joseph, and Newman (2015) found that there is some danger in crowdsourcing data without imposing restrictions. The sample was therefore restricted to residents within the United States. One other requirement for my sample was that individuals currently hold supervising positions. Participants were also required to speak English, to have completed at least 100 previous MTurk surveys, and have at least a 95\% approval rating on MTurk (i.e., 95 out of 100 completions approved), which are suggested requirements to ensure quality data (Bartel-Sheehan \& Pittman, 2016; Peer, Vosgerau, \& Acquisti, 2014). These restrictions ruled out participants who have not provided quality data in the past. These are mostly factors that I controlled using settings on MTurk. The survey additionally screened out participants who indicated they were not supervisors and did not work at least 20 hours a week.

According to simulations by Preacher, Rucker, and Hayes (2007), in order to obtain a moderate effect size $(r=.39)$ at an alpha level of .05 , the sample size $(n)$ for this study needed to be at least 200 . I therefore aimed to collect a sample of 350 participants, as there was concern with careless responding and invalid responses. A total of 483 
responses were collected. After removing repeat responders (individuals who completed the survey more than one time) and incomplete surveys, the sample consisted of 385 individuals. Participants were given an opportunity in the final section of the survey for individuals to be honest about their supervisor status. Specifically, participants were asked as a screening question if they were a supervisor at the beginning of the survey. The final survey item explained that it was the final question and that participants could answer truthfully without fear of penalty; it asked participants if they were really a supervisor. Four individuals indicated they had lied about being a supervisor. Next, those who did not pass attention check items (see Appendix B) were removed from the final sample, diminishing the sample size to 255. Attention check items consisted of both instructed response (e.g., "Please select 'strongly agree."') and bogus items (e.g., "I have visited every country in the world.”; see Huang, Bowling, Liu, \& Li, 2015; Meade \& Craig, 2012). Finally, those who took less than six minutes (about half of the average time spent and a third of the piloted time spent) to complete the survey were removed from the sample, resulting in a final sample of 202 supervisors.

The final sample $(N=202)$ was $52 \%$ male and the majority of participants were white $(82.7 \%)$. Three percent were Hispanic or Latino, 5.9\% were African American, 4.0\% were Asian, $1.5 \%$ were Native American, $0.5 \%$ were Native Alaskan or Pacific Islander, and $2.5 \%$ indicated they were of mixed race/ethnicity. Most reported completion of a 4 -year college degree (44.6\%), with $16.8 \%$ reporting an advanced degree, $12.9 \%$ with a 2-year associates degree, and the remainder (25.7\%) completing high school, a GED, or some college. The average participant age was $40.3(S D=11.66)$. These 
supervisors worked an average of 43.13 hours per week $(S D=7.53)$, have been supervisors for 5.85 years $(S D=4.82)$, and on average supervised 14 employees $(S D=$ 22.71). As mindfulness is a core construct of interest for this study, I asked participants if they practiced mindfulness or meditation and $21.8 \%$ indicated they did.

\section{Procedure}

The survey was developed using Qualtrics and was subsequently posted as a task on MTurk. The survey was initially planned to be open for a week, however, after three days only 75 responses had been collected. In order to make the task more visible, it was republished so it would appear near the top of the list of requests on MTurk. Though this put the survey at risk for repeat responses, republishing multiple times increased the rate at which participants were collected. Over 400 responses were collected after two weeks. Once participants selected the task on MTurk, they were provided with a link to the survey, where they either accepted or denied an online version of informed consent. After responding to screening questions, participants were able to complete the survey.

The survey assessed demographic information (age, gender, race/ethnicity, tenure at current job, marital status, education, hours worked per week, details on their supervising position), and all other included measures (mindfulness, empathic concern, perspective taking, response flexibility, LMX perceptions, workload). Upon completion of the survey on Qualtrics, participants were given a random completion code to submit on MTurk in order to be compensated. This also allowed me to match data from MTurk 
and Qualtrics. Those who failed to pass attention checks ${ }^{1}$, provided an invalid completion code, or had already taken the survey (repeat respondents) were denied compensation.

Accepted participants were paid $\$ 0.50$ within five days of completing the survey.

\section{Measures}

All measures prompted participants to think about the past month while answering the survey items. See Appendix A for a full list of survey items.

Mindfulness. Mindfulness was measured using the Mindful Attention and Awareness Scale (MAAS; Brown \& Ryan, 2003). Each of the 15 items was scored from one to six ('almost always' to 'almost never') and were reverse coded. Brown and Ryan (2003) found that it was extremely easy for individuals to endorse items measuring mindfulness, and therefore decided to reverse code their entire scale to measure "mindlessness" rather than mindfulness. This scale is one of the most commonly used mindfulness scales in the organizational literature and demonstrated an acceptable alpha level of .93. A sample item is "I find myself listening to someone with one ear, doing something else at the same time."

Empathic Concern. The Interpersonal Reactivity Index (IRI; Davis, 1980) was used to measure empathic concern. This sub-scale represents experiences of feelings of warmth, compassion, and concern for others (Davis, 1980). The empathic concern items demonstrated adequate reliability with a Cronbach's alpha of .86. It included seven likert items that were rated from one, "does not describe me well," to five, "describes me very

\footnotetext{
${ }^{1}$ See attention check items in Appendix B. Assessment of these checks were lenient in that there were multiple responses that were acceptable for items that were harder to comprehend or that did not have immediately apparent responses.
} 
well." A sample item is, "I am often quite touched by things that I see happen." Three of these items were reverse coded.

Perspective Taking. Perspective taking was also measured using the IRI (Davis, 1980). Perspective taking represents cognitive empathy, or a proclivity to take on the perspectives of others. The sub-scale refers to experiences of stepping outside oneself to understand others. These seven items demonstrated adequate reliability with a Cronbach's alpha of .84. Response options ranged from one, "does not describe me well," to five, "describes me very well." A sample item is, "before criticizing somebody, I try to imagine how I would feel if I were in their place." Two of these items were reverse coded.

Response Flexibility. I assessed response flexibility using the "alternatives" component of the Cognitive Flexibility Inventory (CFI; Dennis \& Vander Wal, 2010). This portion of the inventory represents one's ability to find multiple alternative explanations for occurrences and behavior, as well as the ability to generate multiple solutions to difficult situations. The scale is composed of 13 items that are responded to on a scale of one, "strongly disagree," to seven, "strongly agree.” It displayed a strong Cronbach's alpha level of .95. A sample item is, "when in difficult situations, I consider multiple options before deciding how to behave."

Leader-Member Exchange. Relationship quality between employees and their leaders was assessed using the LMX-7 (Graen \& Uhl-Bien, 1995). The LMX-7 consists of seven likert type items that were all rated on various scales from one to five (e.g., 'rarely' to 'very often' or 'not at all' to 'fully'). Cronbach's alpha for the LMX-7 was .77. 
A sample item from this scale is "How well does your leader understand your job problems and needs?" The supervisor version of that item would be, "How well do you understand your employee's job problems and needs?" Only items geared towards supervisors were used for this study (employee perceptions were not collected).

Workload. Supervisors' levels of workload were assessed using Spector and Jex's (1998) workload scale. This scale consists of five items that assess the amount and urgency of work that one has. Response options range from one, "very rarely to never" to five, "very frequently." This scale presented an adequate alpha level of .82. A sample item is, "How often did your job leave you with little time to get things done?"

Control Variables and Demographic Information. This study involved several questions to assess demographic variables and potential control variables. Participants were asked about their current work position and if they are currently supervising employees, how many employees they supervise, and how frequently they interact with their employees. Frequency of interaction was assessed using a five item scale. Response options ranged from one, "not at all" to five, "more than once a day." The alpha level for this scale was .77. I also asked about tenure in one's current occupation and how many hours individuals worked in a week. I collected demographic information including age, gender, ethnicity, and education level, in order to assess potential differences between groups. Finally, I asked participants if they practice mindfulness or meditation and if so, for how many days a week and minutes per day. Mindfulness practice is related to how mindful one is, so these questions were necessary to assess any differences that exist between supervisors who do and do not practice mindfulness. 


\section{Results}

\section{Preliminary Analysis}

Upon completion of data collection, data from both MTurk and Qualtrics were combined into a single file. After removing respondents who submitted invalid completion codes, did not pass attention checks, or indicated at the end of the survey that they were not actually supervisors, a sample of 255 individuals remained. The survey was estimated to take about 18 minutes to complete according to pilot surveys. However, the average amount of time spent by MTurk workers was about 12 minutes. For these reasons, I created a cutoff point of six minutes (i.e., half of the average time spent; one third of the expected time spent) for cases to include. Any participants who took less than six minutes to complete the survey were not included in analyses as spending this little time could be an indication of careless responding. The final sample included 202 participants. In addition, all surveys were complete, as participants were not given a completion code until they submitted a complete survey on Qualtrics. Three outliers were detected, two under hours worked per week and one in age. The two work hours were over 120 hours, which is very unlikely. These two cases were therefore excluded pairwise. The age outlier reported they were 1971 years old. It was easily assumed this participant had reported their birth year and it was thus corrected to 46 years old.

Items that were reverse coded (mindfulness scale, items from empathic concern and perspective taking) were reversed in SPSS and mean scores were created for each individual and each scale. A set of confirmatory factor analyses (CFA) was conducted in order to compare a three-factor model to two-factor and one-factor models. In examining intercorrelations among variables, I found that perspective taking and response flexibility 
were strongly correlated $(r=.73, p<.01)$. The CFAs thus allowed me to assess whether perspective taking and response flexibility represented separate factors. Results from the three-factor model demonstrated the best fit $\left(\chi^{2}(321)=932.34, p<.001, \mathrm{CFI}=.84\right.$, RMSEA $=.10)$, indicating that the mediating constructs represented three unique factors. While the three-factor model held the best fit, the fit indices are still poor. Additional CFAs were conducted to explain the poor fit. These additional analyses showed that including a common method factor that consisted of reverse coded items improved fit substantially. It was thus concluded that the reverse coded items in the mediator scales did not fit well with the rest of the items.

I examined correlations between all modeled constructs and potential control variables to determine whether or not particular variables should be included in the analyses. Frequency of interaction was significantly and positively correlated with empathic concern $(r=.23, p<.01)$, perspective taking $(r=.16, p<.05)$, response flexibility $(r=.24, p<.01)$, workload $(r=.19, p<.01)$, and $\operatorname{LMX}(r=.35, p<.01)$. Number of years as a supervisor positively correlated with $\operatorname{LMX}(r=.14, p<.05)$. Gender was associated with both empathic concern $(r=.30, p<.01)$ and workload $(r=$ $.20, p<.01)$. An independent samples $t$-test revealed that females report higher levels of both empathic concern $(t(200)=-4.43, p<.001)$, and workload $(t(200)=-3.89, p<.01)$ than males. Finally, whether or not one practices mindfulness or mediation was associated with perspective taking $(r(202)=.30, p<.05)$. An independent samples $t$-test showed that those who practice mindfulness are significantly higher in perspective taking $(t(200)=2.087, p<.05)$ than those who do not. Frequency of interaction, years as a 
supervisor, gender, and mindful practice were therefore included as covariates in all hypothesis testing. However, including these covariates did not alter the outcomes of the analyses. According to Carlson and $\mathrm{Wu}$ (2012), unless there is a meaningful and sound reason to include control variables, doing so may confound interpretation, rather than enhance it. Inclusion of these variables does not add any meaning to interpretation of the model and they are therefore not included in the final hypothesis testing.

I examined correlations and descriptive statistics of all variables of interest and also viewed histograms to assess normality. I additionally examined Q-Q plots for each variable. Descriptive statistics as well as the histograms and Q-Q plots indicated that response flexibility was skewed to the left, $-1.09(S E=0.17)$, indicating the median for response flexibility was higher than its mean. Mindfulness, LMX, and empathic concern were also slightly skewed to the left, $-.57(S E=0.20),-.56(S E=0.17),-.57(S E=0.17)$, respectively. Perspective taking and workload demonstrated normality. This suggests that this sample was particularly high in response flexibility, empathic concern, mindfulness, and LMX. The means for these variables were $4.13(S D=.64), 3.91(S D=.80), 4.57(S D$ $=.95)$, and $4.10(S D=.52)$, respectively. The mean for perspective taking was $3.77(S D=$ $.75)$ and for workload was $3.52(S D=.77)$. All correlations, means, and standard deviations are listed in Table 1.

\section{Hypothesis Testing}

I utilized Hayes' PROCESS Macro for SPSS (Hayes, 2013; Model 4) as well as linear regression functions in SPSS to test my hypotheses. The theoretical background used to support my hypotheses has not been extensively examined. I thus utilized 
PROCESS as well as Baron and Kenny's (1986) approach towards mediation in order to examine the mechanisms of mindfulness as parallel mediators and in a piecemeal approach. Results using Baron and Kenny's approach are presented first for each mediator followed by findings using PROCESS with bias corrected bootstrapping $(5,000)$. Results from the Baron and Kenny approach can be viewed in Figures 3, 4, and 5, while PROCESS parallel mediation results (direct and indirect effects) are in Table 2.

Baron and Kenny's Piecemeal Approach. Following the first step of Baron and Kenny's approach to mediation, LMX was regressed onto mindfulness without controlling for any of the mediators. Results indicate mindfulness was significantly and positively associated with $\operatorname{LMX}(b=.34, t(201)=5.06, p<.001)$, establishing potential for an effect to be mediated.

Second, empathic concern, perspective taking, and response flexibility were each individually regressed onto mindfulness. Mindfulness was significantly positively associated with empathic concern, $b=.22, t(201)=3.18, p<.01$, perspective taking, $b=$ $.29, t(201)=4.29, p<.001$, and response flexibility, $b=.29, t(201)=4.42, p<.001$. These results support Hypotheses $1 \mathrm{a}, \mathrm{b}$, and c, respectively, as mindfulness positively predicted each of the mediators.

Third, although an implied step in Baron and Kenny's model, in accordance with hypotheses, LMX was regressed onto each of the proposed mediators while holding mindfulness constant. Results found that empathic concern significantly and positively predicted LMX $(b=.38, t(201)=6.04, p<.001)$, as did perspective taking $(b=.41$, $t(201)=6.46, p<.001)$, and response flexibility $(b=.51, t(201)=8.60, p<.001)$. 
Empathic concern, perspective taking, and response flexibility were each individually significantly associated with LMX while controlling for the effect of mindfulness, providing support for Hypotheses $2 \mathrm{a}, \mathrm{b}$, and c.

Finally, LMX was regressed onto mindfulness controlling for the effect of each mediator. Regressing LMX onto mindfulness controlling for empathic concern yielded significant results and mindfulness significantly predicted LMX $(b=.25, t(200)=4.03, p$ $<.001)$. While controlling for perspective taking, mindfulness still significantly and positively predicted $\operatorname{LMX}(b=.22, t(200)=3.44, p<.01)$. Furthermore, controlling for response flexibility, mindfulness was significantly associated with $\operatorname{LMX}(b=.18, t(200)$ $=3.08, p<.01)$. Mindfulness was a significant predictor of LMX while controlling and not controlling for each mediator. However, with the addition of each mediator as a predictor, the beta coefficient for mindfulness decreased. This indicates that empathic concern, perspective taking, and response flexibility are each partial mediators of the relationship between mindfulness and LMX, supporting Hypotheses $3 \mathrm{a}, \mathrm{b}$, and c. In addition, mindfulness still significantly predicted LMX after controlling for these variables, indicating a significant direct effect of mindfulness.

Hayes' PROCESS Macro. Results using the PROCESS macro in SPSS were similar to the piecemeal regression approach. Hypotheses $1 \mathrm{a}, \mathrm{b}$, and c were supported; supervisor mindfulness was significantly and positively related to empathic concern $(b=$ $.19,95 \%$ BC CI $[.07, .30])$, perspective taking $(b=.23,95 \%$ BC CI $[.12, .34])$, and response flexibility $(b=.20,95 \%$ BC CI $[.11, .29])$. Empathic concern was also significantly associated with LMX while controlling for mindfulness $(b=.25,95 \% \mathrm{BC}$ 
CI $[.17, .33])$, as were perspective taking, $(b=.28,95 \%$ BC CI $[.20, .37])$, and response flexibility $(b=.42,95 \%$ BC CI $[.32, .52])$. These results provide additional support for Hypotheses $2 \mathrm{a}, \mathrm{b}$, and c. The mediating effect of empathic concern in the relationship between mindfulness and LMX was also significant, in that mindfulness predicted LMX indirectly through empathic concern $\left(b_{\text {indirect }}=.05,95 \%\right.$ BC CI $\left.[.02, .08]\right)$, and directly $\left(b_{\text {direct }}=.14,95 \%\right.$ BC CI $\left.[.07, .21]\right)$, supporting Hypothesis 3a. There was a significant indirect effect of mindfulness on LMX through perspective taking $\left(b_{\text {indirect }}=.07,95 \% \mathrm{BC}\right.$ CI $[.04, .10])$, as well as a direct effect of mindfulness on $\operatorname{LMX}\left(b_{\text {direct }}=.12,95 \%\right.$ BC CI $[.05, .19])$, providing support for Hypothesis $3 b$. Finally, the indirect effect of mindfulness on LMX through response flexibility was also significant $\left(b_{\text {indirect }}=.08,95 \%\right.$ BC CI $[.04, .14])$, as was the direct effect of mindfulness on LMX $\left(b_{\text {direct }}=.10,95 \% \mathrm{BC}\right.$ CI $[.04, .17])$. This provides support for Hypothesis $3 \mathrm{c}$ that response flexibility partially mediates the relationship between supervisor mindfulness and LMX.

Haye's PROCESS Macro with Parallel Mediators. In addition to testing each mediator individually, they were examined as parallel mediators using both the regression approach and Hayes' PROCESS macro in order to understand the unique variance each mediator predicts in LMX. Thus, in regressing LMX onto all three mediators as well as mindfulness, I found that mindfulness significantly and positively predicted LMX $(b=$ $.16, t(198)=2.78, p<.01)$, as did empathic concern $(b=.21, t(198)=3.16, p<.01)$, and response flexibility $(b=.42, t(198)=5.14, p<.001)$. Perspective taking, however, became non-significant with the inclusion of other mediators $(b=.01, t(198)=.05, p=$ 96). This suggests construct overlap between perspective taking and one of the other 
mediators. A large portion of the variance that perspective taking initially explained was explained by another mediator (likely response flexibility).

Hayes' PROCESS macro is a good approach to examining parallel mediators, as it is possible to enter all variables of interest into the model simultaneously. The analyses thus control for all other predictors in each individual analysis, which allows close examination of individual indirect effects and the unique variance explained in LMX by each mediator. The findings using this approach supported findings using Baron and Kenny's approach. Utilizing model 4 (Hayes, 2013) I entered mindfulness as the independent variable, LMX as the dependent variable, and empathic concern, perspective taking, and response flexibility as parallel mediators. This yielded significant indirect effects through empathic concern (indirect effect $=.03,95 \%$ BC CI $[.01, .06]$ ) and response flexibility (indirect effect $=.07,95 \% \mathrm{BC}$ CI $[.03, .13]$ ), but not through perspective taking (indirect effect $=.001,95 \% \mathrm{BC}$ CI $[-.03, .03]$ ). There was a significant direct effect of mindfulness on $\operatorname{LMX}(b=.09,95 \%$ BC CI $[.03, .15])$. Results suggest empathic concern and response flexibility are both partial mediators of the relationship between mindfulness and LMX, while perspective taking is not. Findings support Hypotheses 3 a and c.

\section{Research Question 1}

Research question 1 proposed a moderating effect of supervisor workload on the indirect effects of mindfulness on LMX. Specifically, I proposed that workload would act as a stage one moderator and would moderate each conditional indirect effect of mindfulness on LMX through (a) empathic concern, (b) perspective taking, and (c) 
response flexibility. I proposed mindful supervisors who are under higher levels of workload will not have the ability to display as high levels of empathic concern, perspective taking, and response flexibility, and thus will not demonstrate as high LMX. The PROCESS Macro for SPSS was also used to assess this effect (Model 7; Hayes, 2013). The test of stage one moderated mediation with 5,000 bias-corrected bootstrapped samples demonstrated that there were no conditional indirect effects for workload on LMX. The moderating effect was non-significant for empathic concern (indirect effect $=$ $-.00,95 \%$ BC CI: $[-.03, .01]$ ), perspective taking (indirect effect $=.00,95 \%$ BC CI: $[-.01$, $.01]$ ), and response flexibility (indirect effect $=-.03,95 \%$ BC CI: $[-.09, .00]$ ). This suggests that workload does not significantly influence LMX and even when supervisors are under high levels of workload, they still display similar levels of LMX through empathic concern, perspective taking, and response flexibility.

There was however a significant interaction between mindfulness and workload that predicted response flexibility. Results from Haye's PROCESS Macro (Model 7; Hayes, 2013) demonstrated that mindfulness significantly predicted response flexibility $(b=.59,95 \%$ BC CI $[.29, .90])$, as did workload $(b=.75,95 \%$ BC CI $[.35,1.14])$, and the interaction term between mindfulness and workload $(b=-.10,95 \%$ BC CI [-.18, .11]). The graph of this interaction effect (see Figure 6) demonstrates that individuals low in mindfulness display similar levels of response flexibility regardless of workload. Individuals high in mindfulness on average display higher response flexibility than those low in mindfulness and, in addition, the magnitude of the relationship between mindfulness and response flexibility is even larger under higher levels of workload. 
There is a positive relationship between mindfulness and response flexibility and under conditions of high workload, this relationship increases.

\section{Additional Analyses}

Several additional analyses were conducted in order to explore potential construct overlap that affected the significance of perspective taking as a mediator. To examine if either empathic concern or response flexibility were taking the significant variance perspective taking was explaining in LMX, three pairs of parallel mediators were conducted using Hayes' PROCESS. First, empathic concern and response flexibility were entered as mediators. Both significantly mediated the relationship between mindfulness and LMX $(b=.03,95 \%$ BC CI $[.01, .06] ; b=.07,95 \%$ BC CI $[.03, .12])$. Second, empathic concern and perspective taking were paired and both served as significant mediators $(b=.03,95 \%$ BC CI $[.01, .06] ; b=.05,95 \%$ BC CI $[.02, .09])$. Finally, in pairing perspective taking with response flexibility, perspective taking became nonsignificant $(b=.02,95 \% \mathrm{BC} \mathrm{CI}[-.01, .05])$, while response flexibility remained significant $(b=.03,95 \% \mathrm{BC} \mathrm{CI}[.03, .12])$. These results confirm that the constructs of response flexibility and perspective taking overlap, such that response flexibility took away a large portion of the variance perspective taking had previously explained in LMX.

Although whether or not participants practice mindfulness or meditation did not make a significant difference in the results of the mediation analyses, the sub-sample of those who reported they do practice was examined to further explore any meaningful differences between these two groups. Of the total 202 participants, 44 reported practicing some type of mindfulness or meditation. Though these participants were not 
significantly higher in mindfulness as those who did not practice, the frequency with which they practiced (days per week) was significantly correlated with mindfulness ( $r=$ $.32, p<.01$ ). However, the time spent practicing (minutes per day) was not significantly correlated with mindfulness. Days per week were multiplied by minutes per day in order to see if total time spent practicing per week was related to mindfulness. Total time was not correlated with mindfulness. Though this sub-sample is small, these associations interestingly indicate that the frequency of practice may have a larger impact on mindfulness than time spent practicing mindfulness per day or total time spent per week. 


\section{Discussion}

Though mindfulness at work is a growing area of research, the influence of interpersonal aspects of supervisor mindfulness on supervisor-subordinate relationships and leader behaviors was unexamined. This study sought to fill this gap by examining whether or not supervisor mindfulness is associated with higher quality supervisorsubordinate relationships. In addition, I utilized a theoretical framework to examine the affective, cognitive, and behavioral mechanisms of mindfulness that foster high quality relationships.

\section{Contributions}

Findings were mostly consistent with hypotheses, providing support for a theoretical framework that has not been previously supported to my knowledge (Glomb et al., 2011). Supervisor mindfulness was positively associated with empathic concern, perspective taking, and response flexibility. These three sub-processes were positively related to supervisor perceptions of LMX, though only empathic concern and response flexibility mediated the relationship between supervisor mindfulness and LMX. In line with theory, this research suggests that supervisors who follow a behavioral pattern of mindfulness are able to decouple themselves from experiences and events, decrease their use of automatic mental processes, and have increased awareness of their physiological regulation. This allows them to demonstrate higher levels of empathic concern and response flexibility (Glomb et al., 2011), which are then associated with better perceptions of relationship quality. Processes of mindfulness were associated with higher quality relationships with employees and the assertion that mindful supervisors are able 
to be mindfully present creating intrapersonal attunement (Siegel, 2007) was thus supported.

In addition to utilizing Glomb and colleagues theoretical framework, the three proposed mechanisms were aligned, such that they represented affective, cognitive, and behavioral mechanisms of mindfulness. Mindfulness was indeed associated with higher levels of empathic concern (affective), perspective taking (cognitive), and response flexibility (behavioral), supporting the notion that mindfulness as present moment attention and awareness generates sub-processes that are affective, cognitive, and behavioral. However, only empathic concern and response flexibility significantly mediated the relationship. Additional analyses revealed that the constructs of perspective taking and response flexibility overlapped considerably. In closer examination of the construct items, response flexibility seems to represent a cognitive scale, providing the conclusion that mindfulness is associated with affective and cognitive processes. This endorses the proposition that mindfulness is associated with interpersonal outcomes by relating to improvements in emotional and thought processes within individuals.

Research has shown that mindfulness has a positive influence on both romantic and familial relationships (Atkinson, 2013; Barnes et al., 2007; Block-Lerner et al., 2007; Cozolino, 2006; Davis \& Oathout, 1987; Gambrel \& Keeling, 2010; Siegel, 2007; Teasdale et al., 2002). This study sought to express how leader mindfulness might influence supervisor-subordinate relationship quality through several affective, cognitive, and behavioral mechanisms. Examining this association is particularly important given the high level of influence supervisor-subordinate relationships have on organizational 
outcomes (e.g., job satisfaction, organizational commitment, citizenship behaviors, turnover, burnout; Dulebohn et al., 2012; Huang et al., 2010) and employee outcomes (Gilbreath \& Benson, 2004; Kelloway \& Barling, 2010; Martin et al., 2016; Skakon et al., 2010). Findings from this study show that, similar to other interpersonal relationships, mindfulness in supervisors is associated with relationship quality between supervisors and subordinates. The link between LMX and mindfulness, both directly and through mediating mechanisms of empathic concern and response flexibility, indicates that supervisor mindfulness may influence employee outcomes. High quality supervisorsubordinate relationships characterized by mutual trust, caring, concern, and support lead to thriving employees, work groups, and organizations. Positive LMX relationships are associated with improved job satisfaction, employee well-being, reduced employee stress (Gilbreath \& Benson, 2004; Epitropaki \& Martin, 2005; Skakon et al., 2010), while poor leadership is related to employee stress and burnout (Skakon et al., 2010). If mindfulness assists in the development of high quality supervisor-subordinate relationships, it may also help employees to thrive and organizations to flourish.

Workload was examined as a stage one moderator of the indirect effects of mindfulness on LMX through empathic concern, perspective taking, and response flexibility in order to gain an understanding of how processes of mindfulness manifest under high levels of work demands. The moderation was non-significant for each indirect effect, but there was a significant interaction between mindfulness and workload in predicting response flexibility. Those who were less mindful demonstrated, on average, low levels of response flexibility regardless of workload. Higher mindfulness is 
associated with increasing response flexibility and under higher levels of workload, the magnitude of this relationship grows. Under higher levels of workload, the relationship between mindfulness and response flexibility is stronger than when under lower levels of workload. These results are surprising in that response flexibility grew strong with increasing levels of both mindfulness and workload. It is possible that this association is stronger under high workload as high demands necessitate higher attention and awareness of what is occurring in the present moment, as well as increased ability to respond to the environment.

Finally, though the subsample of individuals who indicated they regularly practiced some sort of mindfulness or meditation is too small to come to any definite conclusions, follow-up analyses on this subset of people Overall, these findings provide intriguing insights into the interpersonal functions of mindfulness at work and how supervisor mindfulness can improve leadership outcomes and supervisor-subordinate relationship quality.

\section{Limitations and Implications for Future Research}

The proposed study has several limitations that should be addressed in future research. First, I did not have the resources to use and assess mindfulness as a leadership intervention. For this reason, I could not train mindfulness and instead assessed it as a behavioral pattern. However, as the relationship between mindfulness and LMX was significant, it is possible that interventions training mindfulness to supervisors may improve leader behavior. Future research should address this limitation by implementing and evaluating mindfulness interventions and subsequently examining not only changes 
in levels of mindfulness, but also changes in workplace outcomes such as LMX. In addition, support was provided for the mediating mechanisms of empathic concern and response flexibility, demonstrating that interpersonal processes of mindfulness are associated with leader behavior. Future research can explore other leadership constructs, such as supervisor support, to establish the effects of mindfulness on interpersonal working relationships. Mindfulness had a positive impact on LMX through "softer" leadership processes, and while individuals do not often value soft skills in leadership, they play an important role in producing positive outcomes for subordinates and organizations.

It is also important that practitioners conduct research and consider different types of mindfulness training before implementing interventions. There are many different ways that mindfulness can be trained and there are additionally many formats, periods of time, and context in which it can be trained. More traditional mindfulness interventions are eight weeks long and involve several forms of practice, while some are geared towards specific outcomes (e.g., compassion). Mindfulness should not be considered a cure-all for organizational and employee outcomes. It is thus important that organizations, practitioners, and researchers consider specific outcomes they wish to reach via training, before selecting the type of mindfulness training.

Second, this study aimed to examine three affective, cognitive, and behavioral mechanisms. Results examining the three mechanisms as parallel mediators demonstrated only empathic concern (affective) and response flexibility (behavioral) as significant mediators. Follow-up analyses indicated that the measures of response flexibility and 
perspective taking had considerable overlap, rendering perspective taking as a nonsignificant mediator when included in the parallel mediation model. In closer examination of the items in both scales, while some of the response flexibility items represents behavioral intentions, the scale as a whole reflects more cognition than it does behavior. Despite this limitation, findings still support the assertion that there are unique affective, cognitive, and/or behavioral mechanisms that mediate the relationship between mindfulness and relationship quality, as empathic concern and response flexibility were significant mediators. This indicates that mindfulness, as an internal process, alters the way individuals actively think and feel about the present moment. Future research should strive to establish behavioral mediators in this relationship or develop measures of behavioral indicators of mindfulness, such as response flexibility. This would help comprehension of how mindful processes unfold both internally and externally.

Third, only supervisor responses were collected, putting this study at risk for common source bias. Subordinate perceptions of leadership are arguably just as, if not more important to consider than leaders' perceptions of their own leadership. Additionally, supervisors and subordinates often do not agree in their perceptions of leadership (Schriesheim, Neider, \& Scandura, 1998; Xin, 2004). However, perceptions are not always accurate representations of reality, making it impossible to know whose perception of LMX (supervisor versus subordinate) is more accurate. Future research should aim to collect data from both supervisors and their subordinates in order to gain the most realistic perspective of a dyad's level of LMX. This may offer more insight into how leader mindfulness impacts LMX quality in reality. Consideration of measurement 
source also provides an additional set of more complicated and interesting questions. For example, there may be a difference in supervisor versus employee reports of supervisor mindfulness. It would be interesting to examine how employees perceive leader mindfulness to see if there is any distinction between employee perceptions of genuine or insincere mindfulness. This perception may impact perceptions of leadership, such that when employees believe their supervisors are not sincerely mindful, the relationship between mindfulness and leadership may not exist or may even be negative.

Fourth, though findings supported the hypothesis that supervisor mindfulness relates to higher levels of LMX, supervisor tendency to behave mindfully may also have positive outcomes for employees at the individual level. Supervisor mindfulness may result in improvements in employee health and well-being, job satisfaction, and performance. Future research should assess multiple outcomes to see if mindfulness might be used as a method of improving relationships, as well as other outcomes concurrently. Because of the relational nature of mindfulness, it is likely that cross-level effects exist. The way mindfulness in one person impacts another should be examined.

Fifth, while I did attempt to research a condition (i.e., workload) under which the relationship between mindfulness and LMX may be attenuated, the moderating effect was not significant. Future research should evaluate other potential moderating effects (e.g., employee perceptions of supervisor mindfulness; see above) in order to understand factors that exacerbate and/or attenuate the effects of mindfulness on organizational and leadership outcomes. Though there was no significant moderating effect of workload, the significant interaction between mindfulness and workload provides future directions that 
could demonstrate the benefits of mindfulness in handling high levels of job demands. These relationships should be explored more as findings were unexpected and inconsistent with theory, but it is possible that mindfulness can be a utilized as training for leaders and employees in learning how to effectively handle one's workload.

Finally, there were some design flaws that future research should improve upon. I utilized Amazon's Mechanical Turk to obtain data. MTurk has been demonstrated as an excellent source of quality data (Bartel-Sheehan \& Pittman, 2016; Buhrmester et al., 2011); however, this method is not without restrictions. I know little about exactly who the current participants are or what the nature of their work is. If online platforms are used in the future, it would be helpful to obtain qualitative data that provides insight into who the participants are and what their work requires. Second, this study is of a crosssectional nature, which does not allow me to infer causality. It is possible that reverse causation exists, and LMX influences one's level of mindfulness and empathy. Future studies should thus utilize daily diary designs to observe more state-like processes of mindfulness, as well as longitudinal studies that assess changes in mindfulness and in its outcomes. Finally, all constructs in this study are captured using survey measures. While they have been well validated and demonstrated high reliabilities, this put the study at risk for common method bias. Future research should consider assessing mindfulness and its mechanisms with qualitative and/or objective forms of data. The theoretical rationale of my arguments dictates that the secondary processes of mindfulness occur partially because of increased attention to physiological regulation. As such, it would also be interesting to examine physiological outcomes of mindfulness for two reasons. First, 
improved physiological regulation may mediate the relationship between mindfulness and empathy or other processes, which may provide evidence for a deeper internal mechanism. Second, as mindfulness has been related to multiple indicators of health and well-being, research that observes physiological outcomes could provide more support for mindfulness predicting health related outcomes.

\section{Practical Implications}

The proposed study has several potential implications for practice. Though I measured mindfulness as an experience or behavioral pattern, previous research has proposed that mindfulness can be learned via training (Brown \& Ryan, 2003; Quaglia et al., 2015). Mindfulness is frequently conceptualized in the literature as a trait, but I argue that it is a learned trait, not inherited. Learned traits are gained via experiences, surroundings, upbringing, and observation, and thus can be habituated and trained (McClelland, 1951). Therefore, while mindfulness does differ between people, these differences may exist due to experience and practice. Most individuals, if not all, have the potential to learn and exhibit high levels of mindfulness. Because mindfulness can be learned, practitioners should weigh the option of providing mindfulness trainings for employees and particularly leaders.

Second, analyses showed that mindfulness was predictive of empathic concern, perspective taking, and response flexibility. This supports the notion that mindfulness influences interpersonal constructs. As such, researchers and practitioners alike who are interested in strengthening interpersonal skills might consider mindfulness training as an option. Many types of mindfulness training already exist and have been evaluated as 
interventions within organizations. It is likely that different types of mindfulness

interventions lead to slightly different outcomes, which could be a fruitful future

direction to follow. It is possible that utilizing a loving-kindness mindfulness intervention (see Fredrickson, Cohn, Coffey, Pek, \& Finkel, 2008) may be particularly effective in increasing empathy and response flexibility.

Third, the three mediating mechanisms also each individually predicted LMX.

Literature tends to focus more heavily on the outcomes of LMX than on the antecedents. These findings emphasize the importance of soft and often undervalued leadership skills like empathy. Training these overlooked skills can improve leader behavior, and particularly supervisor-subordinate relationships. This should be an area of interest for practitioners, as we know the importance of support and relationships at work and how influential a role one's supervisor plays in one's life.

Fourth, in addition to mindfulness directly predicting LMX, findings showed that higher levels of mindfulness predicted higher empathic concern and response flexibility, which in turn predicted more positive perceptions of LMX. The sample collected for this study was of supervisors, so practitioners should consider leader-focused mindfulness training as a way to improve supervisor-subordinate relationships and leader behaviors. Training mindfulness particularly for leaders may be more effective than providing mindfulness training for all employees, as it may improve leader outcomes. However, I should note that employees can still benefit from practicing mindfulness themselves. First, training leaders would cost less than providing training for everyone, and second, providing training for leaders can provide positive leadership outcomes (i.e., improved 
LMX) and positive outcomes for employees. Specifically, training leaders to be more mindful at work can impact employee job satisfaction, psychological well-being, and performance, through improved leadership perceptions. Furthermore, leaders can be trained in improving LMX, but mindfulness trainings may provide benefits above and beyond LMX training alone. Mindfulness could improve LMX in addition to individual well-being and performance (Good et al., 2016), and other outcomes for employees.

Overall, these findings suggest that mindfulness should be considered as a training option to benefit leadership skills and relationship quality between supervisors and subordinates. In addition, mindfulness trained in leaders has the potential to benefit employee outcomes. If leaders learn to be more mindful at work, they may demonstrate more empathy and response flexibility towards employees, which may improve employees' perceptions of their leaders as well as their satisfaction at work and in life, along with their well-being. Mindfulness in one person likely positively affects other individuals, and as these improvements unfold, there could potentially be higher-level effects where organizational climates shift to instilling responsiveness, empathy, and positive interactions among workers.

\section{Conclusion}

Research on mindfulness within the work context is still limited. Though empirical research has well established the effect of individual level mindfulness on a variety of performance and well-being outcomes, the impact that mindfulness in one individual has on another has gone unexplored. Mindfulness, as it has much to do with reacting to and interacting with stimuli in the environment, is an inherently relational 
construct. The goal of this study was to examine mindfulness in supervisors and how it may affect leader behaviors, specifically LMX, through three mediating mechanisms (empathic concern, perspective taking, response flexibility). Findings support an unexplored framework and provide initial evidence that supervisor mindfulness predicts supervisor-employee relationship quality both directly and via empathic concern and response flexibility. Due to the positive outcomes of high quality LMX and positive leadership in general, it is of interest for researchers and organizations to further examine mindfulness in leaders and outcomes for leadership, employees, and organizations. 


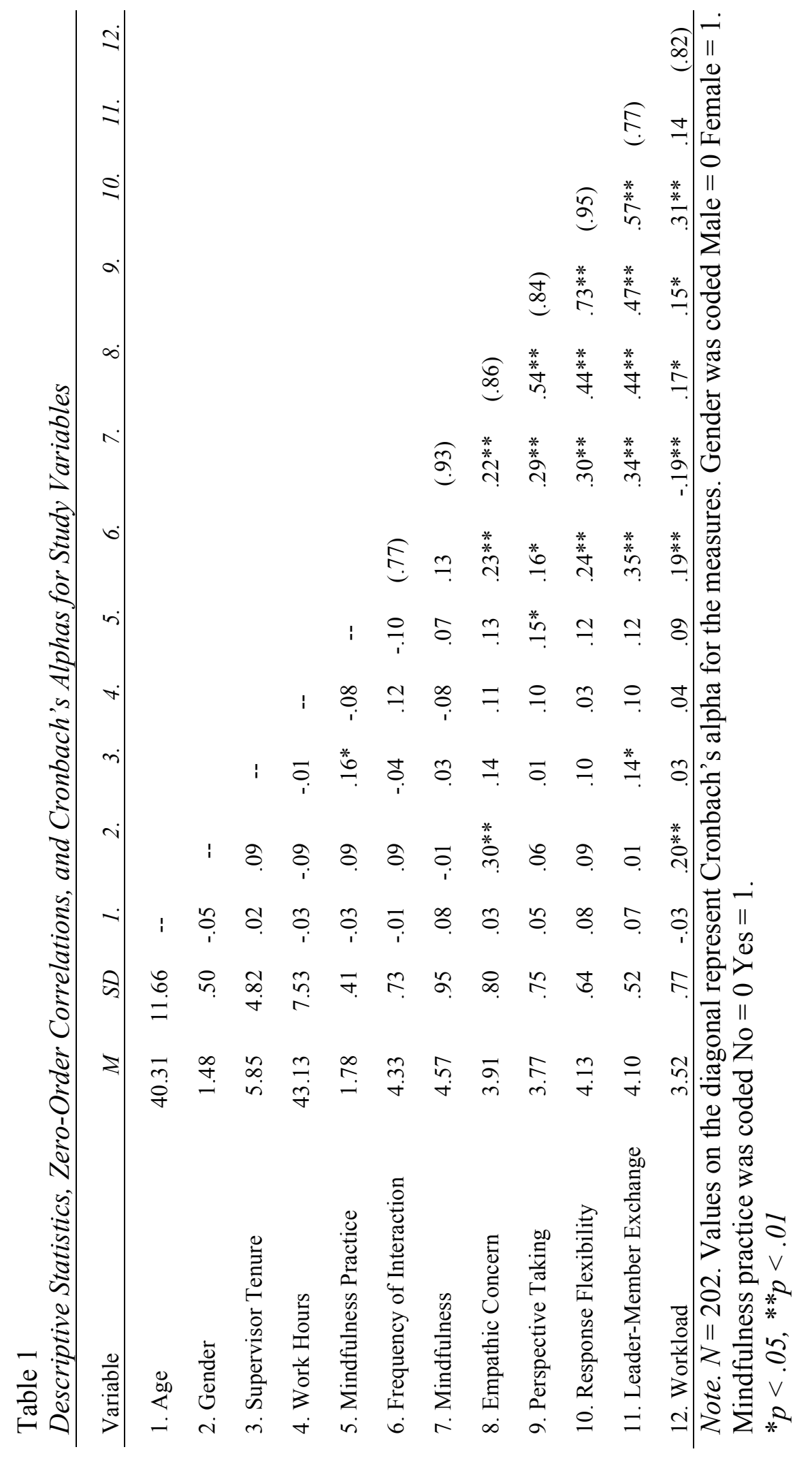




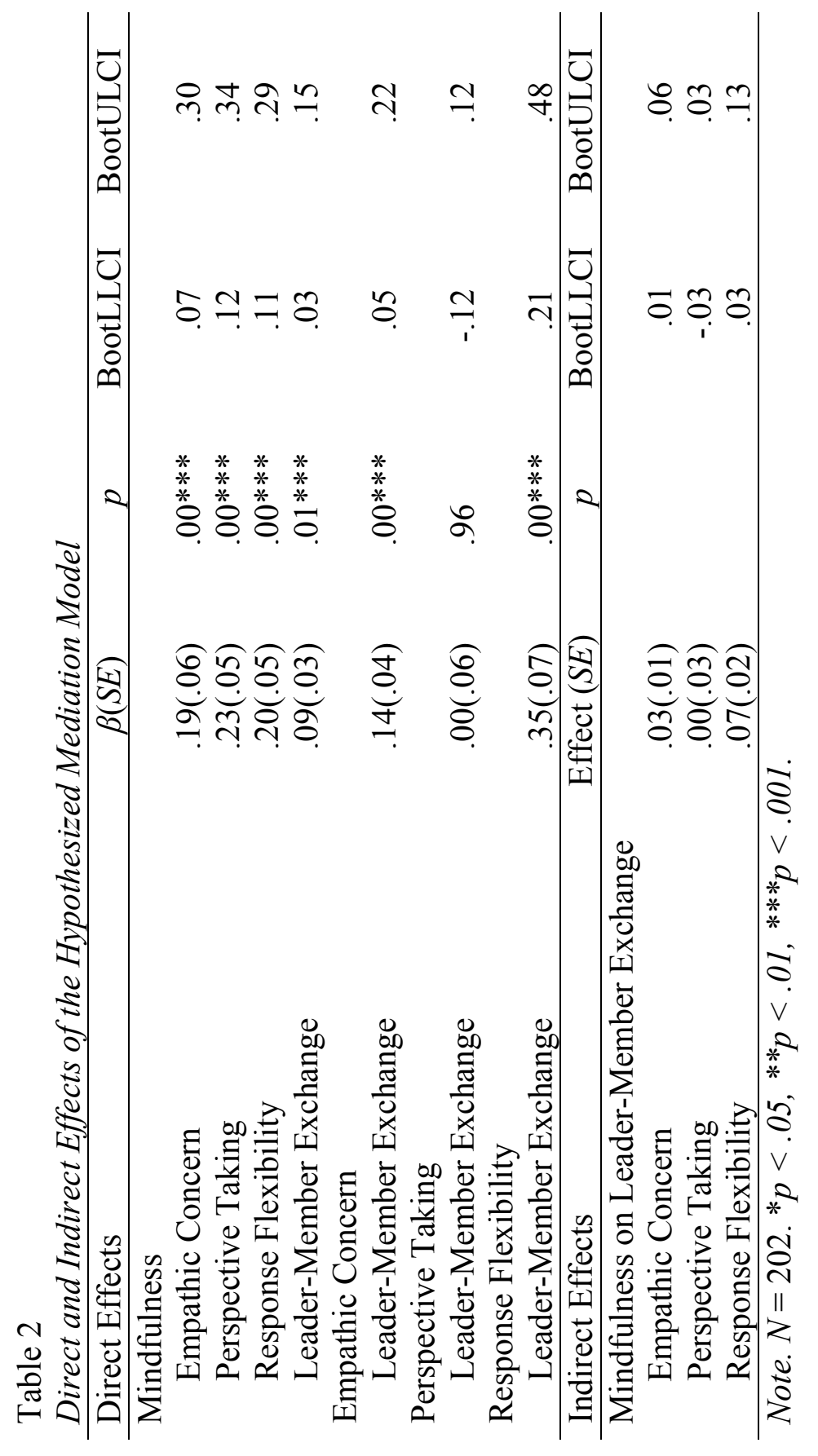




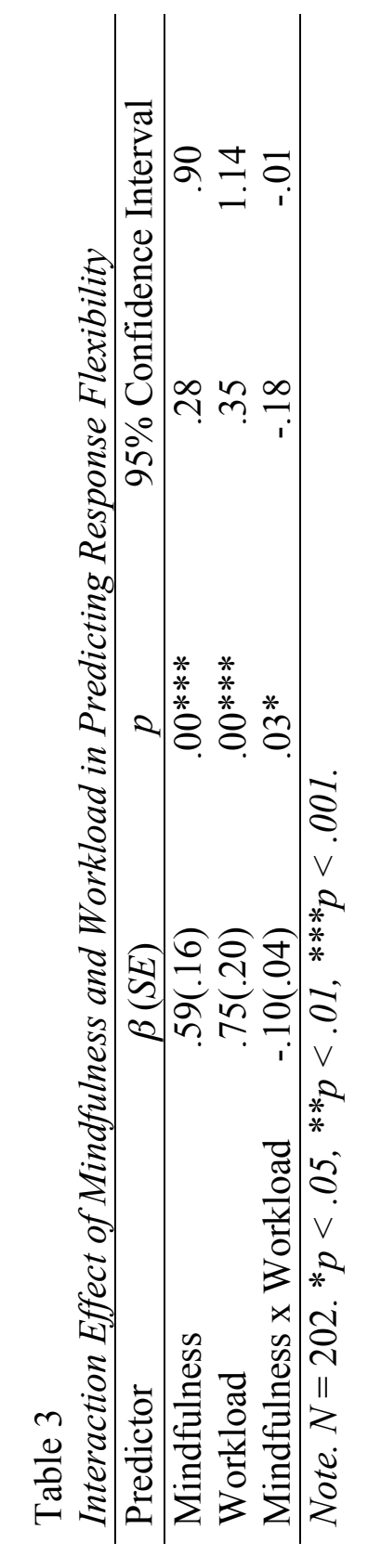




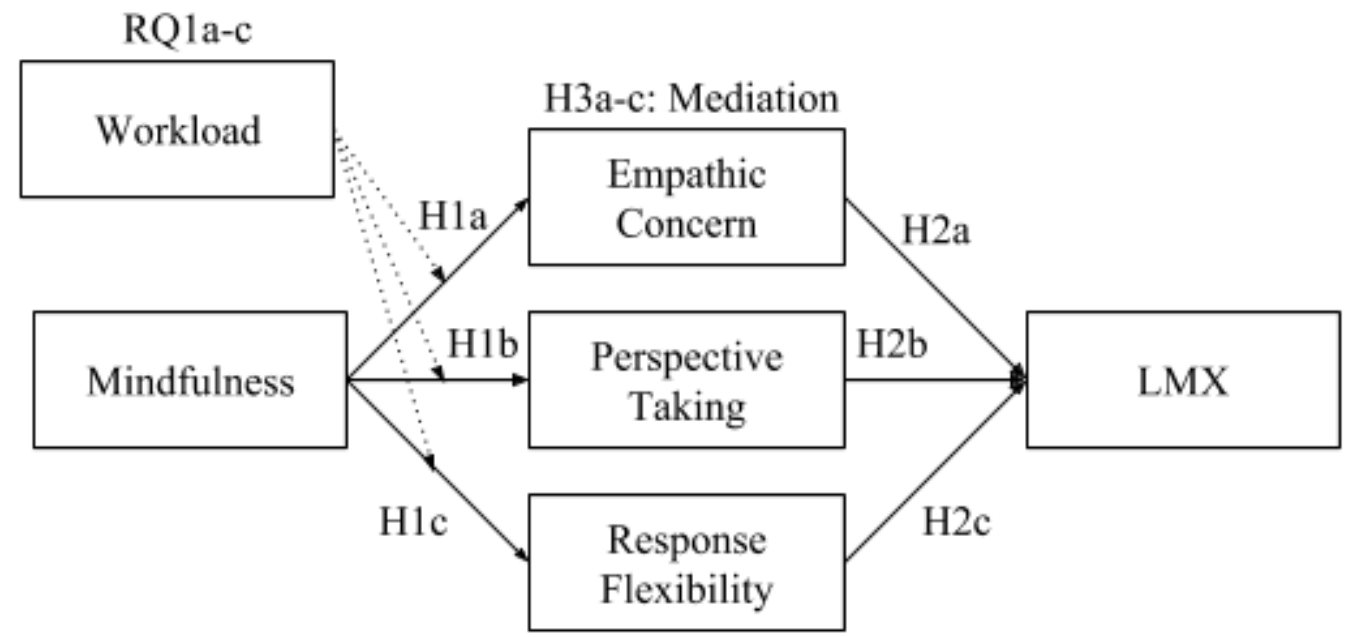

Figure 1. Hypothesized Moderated Mediation Model.

Note. Solid arrows represent proposed hypotheses. Dashed arrows represent research questions. 


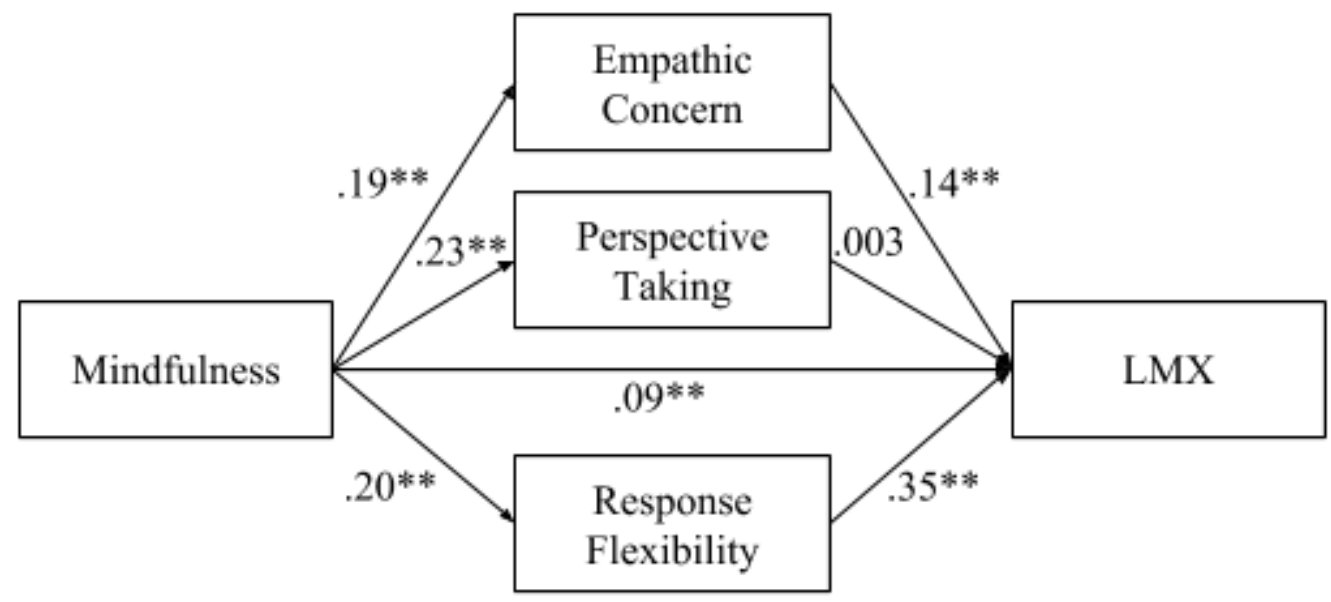

Figure 2. Statistical Model with Beta Coefficients for Parallel Mediation. $N=202 . * p<.05, * * p<.01, * * * p<.001$. 


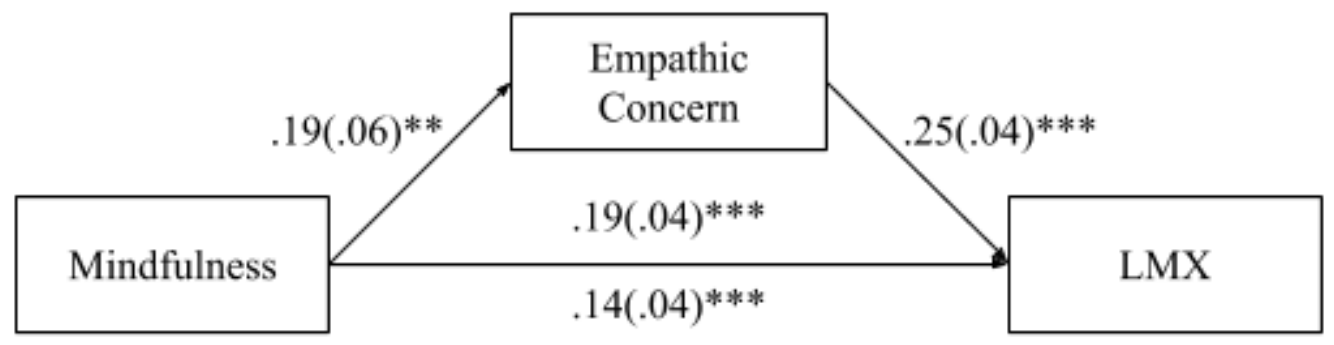

Figure 3. Piecemeal Mediation Results with Empathic Concern.

Note. Paths are labeled with their unstandardized beta estimates and standard errors. The estimate on the inside represents the c path, while the estimate on the outside represents the c'path.

$N=202 .{ }^{*} p<.05, * * p<.01, * * * p<.001$. 


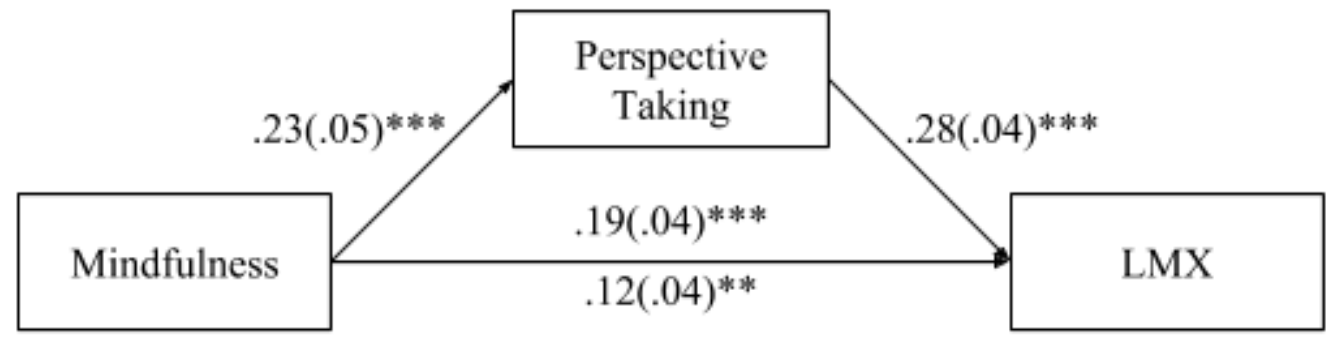

Figure 4. Piecemeal Mediation Results with Perspective Taking.

Note. Paths are labeled with their unstandardized beta estimates and standard errors. The estimate on the inside represents the $\mathrm{c}$ path, while the estimate on the outside represents the c' path.

$N=202 .{ }^{*} p<.05, * * p<.01, * * * p<.001$. 


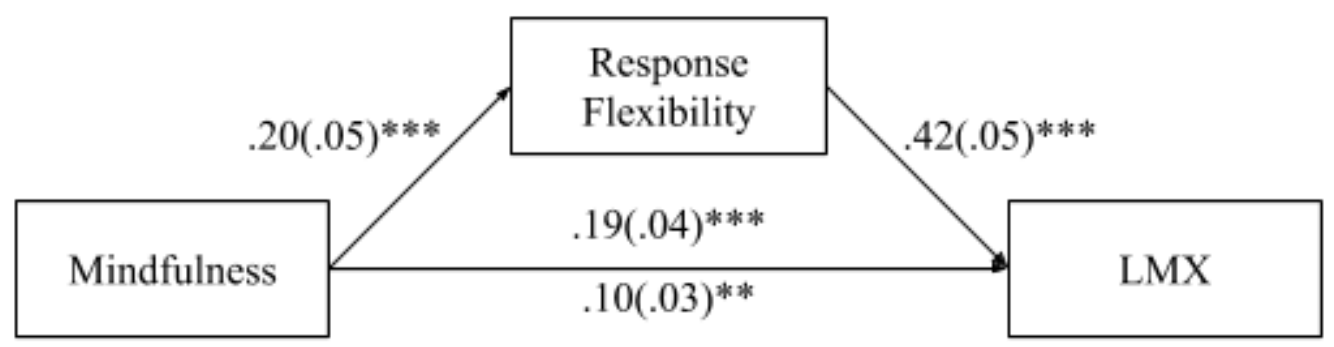

Figure 5. Piecemeal Mediation Results with Response Flexibility.

Note. Paths are labeled with their unstandardized beta estimates and standard errors. The estimate on the inside represents the c path, while the estimate on the outside represents the c'path.

$N=202 .{ }^{*} p<.05, * * p<.01, * * * p<.001$. 


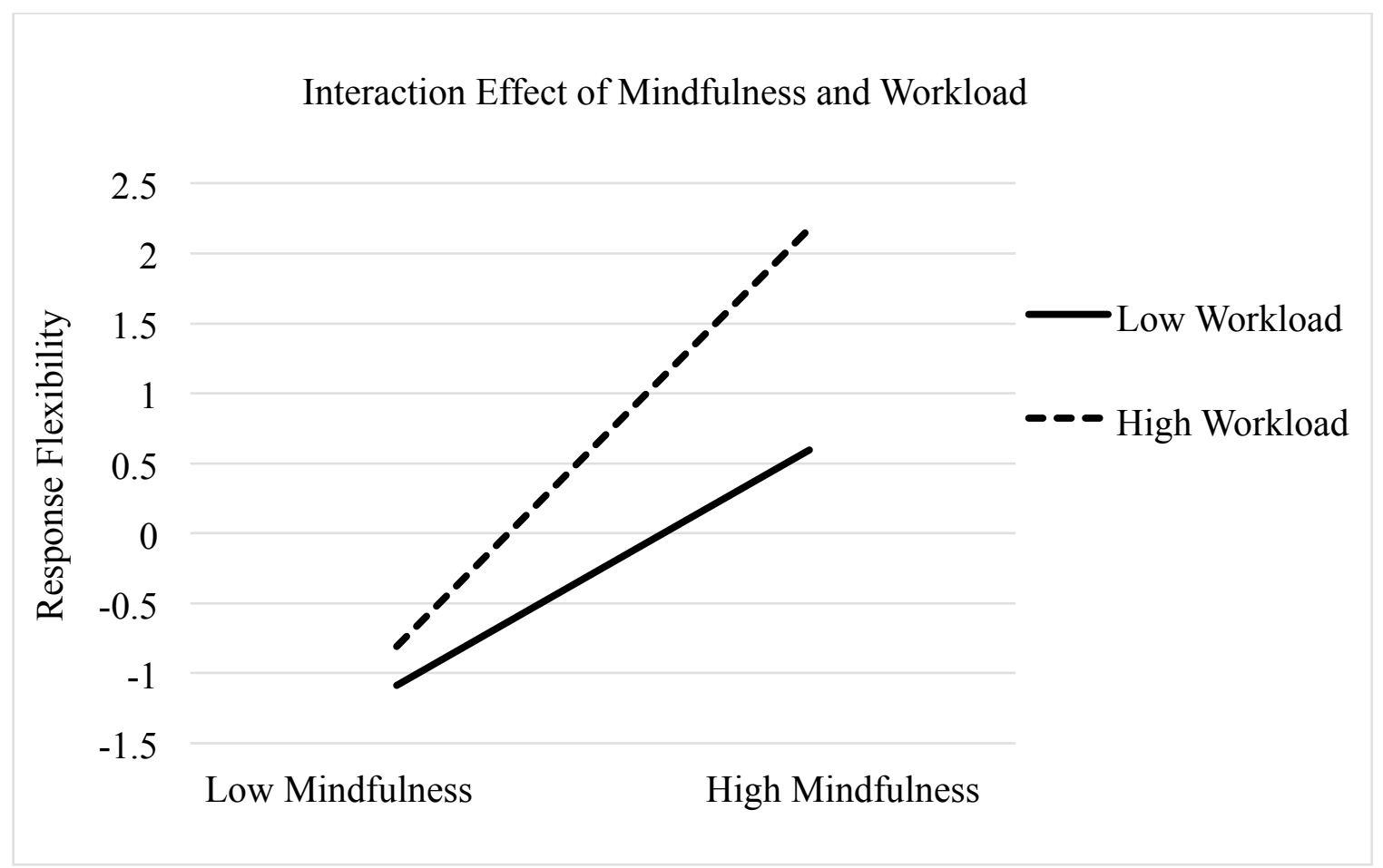

Figure 6. Interaction Effect of Mindfulness and Workload in Predicting Response Flexibility. 


\section{References}

Allen, T. D., \& Kiburz, K. M. (2012). Trait mindfulness and work-family balance among working parents: The mediating effects of vitality and sleep quality. Journal of Vocational Behavior, 80, 372-279. doi: 10.1016/j.jvb.2011.09.002

Ashforth, B. E. (2001). Role transitions in organizational life: An identity-based perspective. Mahwah, NJ: Erlbaum.

Atkinson, B. J. (2013). Mindfulness training and the cultivation of secure, satisfying couple relationships. Couple and Family Psychology: Research and Practice, 2(2), 73-94. doi: 10.1037/cfp0000002

Baer, R. A., Smith, G. T., \& Allen, K. B. (2004). Assessment of mindfulness by selfreport: The Kentucky Inventory of Mindfulness Skills. Assessment, 11, 191-206. doi: $10.1177 / 1073191104268029$

Bakker, A. B., \& Demerouti, E. (2007). The job demands-resources model: State of the art. Journal of Managerial Psychology, 22(3), 309-328. doi: $10.1108 / 02683940710733115$

Bakker A. B., Shimazu A., Demerouti E., Shimada K., Kawakami N. (2011). Crossover of work engagement among Japanese couples: Perspective taking by both partners. Journal of Occupational Health Psychology, 16, 112-125.doi: $10.1037 / \mathrm{a} 0021297$

Bargh, J. A. (1994). The four horsemen of automaticity: Awareness, efficiency, intention, and control in social cognition. In: R. S. Wyer, Jr. \& T. K. Srull (Eds), Handbook of social cognition, 1-40. Hillsdale, NJ: Erlbaum. 
Barnes, S., Brown, K.W., Krusemark, E., Campbell, W.K., \& Rogge, R.D. (2007). The role of mindfulness in romantic relationship satisfaction and responses to relationship stress. Journal of Marital and Family Therapy, 33(4), 482-500. doi: 10.1111/j.1752-0606.2007.00033.x

Baron, R. M., \& Kenny, D. A. (1986). The moderator-mediator variable distinction in social psychological research: Conceptual, strategic, and statistical considerations. Journal of Personality and Social Psychology, 51(6), 1173-1182.

Bartel-Sheehan, K., \& Pittman M. (2016). Amazon's Mechanical Turk for academics. Irvine, CA: Melvin \& Leigh.

Baumeister, R. F., \& Leary, M. R. (1995). The need to belong: Desire for interpersonal attachments as a fundamental human motivation. Psychological Bulletin, 117, 497-529.

Bazarko, D., Cate, R.A., Azocar, F., \& Kreitzer, M.J. (2013). The impact of an innovative mindfulness-based stress reduction program on the health and well-being of nurses employed in a corporate setting. Journal of Workplace Behavioral Health, 28(2), 107-133. doi: 10.1080/15555240.2013.779518

Beitel, M., Ferrer, E., \& Cecero J. J. (2005). Psychological mindedness and awareness of self and others. Journal of Clinical Psychology, 61(6), 739-750. doi: 10.1002/jclp.20095

Birnie, K., Speca, M., \& Carlson, L. E. (2010). Exploring self-compassion and empathy in the context of mindfulness-based stress reduction (MBSR). Stress and Health, 26, 359-371. doi: 10.1002/smi.1305 
Bishop, S. R., Lau, M., Shapiro, S., Carlson, L., Anderson, N. D., Carmody, J., ... Devins, G. (2004). Mindfulness: a proposed operational definition. Clinical Psychology: Science and Practice, 11(3), 230-241. doi: 10.1093/clipsy/bph077 Blau, P. M. (1964). Exchange and power in social life. New York: John Wiley. Block-Lerner, J., Adair, C., Plumb, J. C., Rhatigan, D. L., \& Orsillo, S. M. (2007). The case for mindfulness-based approaches in the cultivation of empathy: Does nonjudgmental, present-moment awareness increase capacity for perspectivetaking and empathic concern? Journal of Marital and Family Therapy, 33, 501516. doi: 10.1111/j.1752-0606.2007.00034.X

Bono, J. E., \& Yoon, D. J. (2012). Positive supervisory relationships. In L. Turner de Tormes Eby \& T. D. Allen (Eds.), Personal relationships: The effect on employee attitudes, behavior, and well-being, 43-66. New York, NY: Routledge Taylor \& Francis Group.

Brendel, W., \& Bennett, C. (2016). Learning to embody leadership through mindfulness and somatics practice. Advances in Developing Human Resources, 18(3), 409425. doi: $10.1177 / 1523422316646068$

Brown, K. W., \& Ryan, R. M. (2003). The benefits of being present: Mindfulness and its role in psychological well-being. Journal of Personality and Social Psychology, 84, 822-848. doi: 10.1037/0022-3514.84.4.822

Brown, K.W., Ryan, R.M., \& Creswell, J.D. (2007). Mindfulness: Theoretical foundations and evidence for its salutary effects. Psychological Inquiry, 18(4), 211-237. doi: : 10.1080/10478400701598298 
Buckingham, M., \& Coffman, C. (1999). First, break all the rules: What the world's greatest managers do differently. New York, NY: Simon \& Schuster.

Buhrmester, M., Kwang, T., \& Gosling, S. D. (2011). Amazon’s Mechanical Turk: A new source of inexpensive, yet high-quality, data? Perspectives on Psychological Science, 6, 3-5. doi: 10.1177/1745691610393980

Carlson, K. D., \& Wu, J. (2012). The illusion of statistical control: Control variable practice in management research. Organizational Research Methods, 15(3), 413435. doi: $10.1177 / 1094428111428817$

Carmody, J., Baer, R. A., Lykins, E. L. B., \& Olendzki, N. (2009). An empirical study of the mechanisms of mindfulness in a mindfulness-based stress reduction program. Journal of Clinical Psychology, 65(6), 613-626. doi: 10.1002/jclp.20579

Carson, S. H., \& Langer, E. J. (2006). Mindfulness and self-acceptance. Journal of Rational-Emotive \& Cognitive-Behavior Therapy, 24(1), 29-43. doi: $10.1007 / \mathrm{s} 10942-006-0022-5$

Chalmers Mill, W. (2010). Training to survive the workplace of today. Industrial and Commercial Training, 42(5), 270-273. doi: 10.1108/00197851011057573

Chambers, R., Gullone, E., \& Allen, N. B. (2009). Mindful emotion regulation: An integrative review. Clinical Psychology Review, 29, 560-572. doi: 10.1016/j.cpr.2009.06.005

Ciulla, J. B. (2010). Being there: Why leaders should not "fiddle" while Rome burns. Presidential Studies Quarterly, 40(1), 38-56. doi: 10.1111/j.17415705.2009.03753.x 
Cohen, S., \& Wills, T. A. (1985). Stress, social support, and the buffering hypothesis. Psychological Bulletin, 98(2), 310-357.

Colbert, A. E., Bono, J. E., \& Puranova, R. K. (2008). Flourishing via workplace relationships: Moving beyond instrumental support. Academy of Management Journal, 59(4), 1199-1223. doi: 10.5465/amj.2014.0506

Cozolino, L. (2006). The neuroscience of human relationships: Attachment and the developing social brain. New York: Norton.

Crain, T. L., Schonert-Reichl, K. A., \& Roeser, R.W. (2016). Cultivating teacher mindfulness: Effects of a randomized controlled trial on work, home, and sleep outcomes. Journal of Occupational Health Psychology. Advance online publication. doi: 10.1037/ocp0000043

Cropanzano, R., \& Mitchell, M. S. (2005). Social exchange theory: An interdisciplinary review. Journal of Management, 31(6), 874-900. doi:

$10.1177 / 0149206305279602$

Culbertson, S. S., Huffman, A. H., \& Alden-Anderson, R. (2009). Leader-member exchange and work-family interactions: The mediating role of self-reported challenge- and hindrance- related stress. The Journal of Psychology, 144(1), 1536. doi: $10.1080 / 00223980903356040$

Dane, E., \& Brummel, B. J. (2013). Examining workplace mindfulness and its relations to job performance and turnover intention. Human Relations, 67(1), 105-128. doi: $10.1177 / 0018726713487753$ 
Davis, M. H. (1980). A multidimensional approach to individual differences in empathy. JSAS Catalog of Selected Documents in Psychology, 10, 85.

Davis, M. H. (1983). Measuring individual differences in empathy: Evidence for a multidimensional approach. Journal of Personality and Social Psychology, 44, 113-126. doi: 10.1037/0022-3514.44.1.113

Davis, M.H. \& Oathout, H.A. (1987). Maintenance of satisfaction in romantic relationships: Empathy and relational competence. Journal of Personality and Social Psychology, 53(2), 397-410. doi: 10.1037/0022-3514.53.2.397

de Lisle, S. M., Dowling, N. A., \& Allen, J. S. (2012). Mindfulness and problem gambling: A review of the literature. Journal of Gambling Studies, 28, 719-739. doi: 10.1007/s10899-011-9284-7

Dennis, J. P., \& Vander Wal, J. S. (2010). The cognitive flexibility inventory: instrument development and estimates of reliability and validity. Cognitive Therapy Research, 34, 241-253. doi: 10.1007/s10608-009-9276-4

Dulebohn, J.H., Bommer, W.H., Liden, R.C., Brouer, R.L., \& Ferris, G.R. (2011). A meta-analysis of antecedents and consequences of leader-member exchange: Integrating the past with an eye toward the future. Journal of Management, 38(6), 1715-1759. doi: 10.1177/0149206311415280

Dutton, J. E., \& Heaphy, E. D. (2003). The power of high-quality connections. In: K.S. Cameron, J. E. Dutton \& R. E. Quinn (Eds), Positive organizational scholarship: Foundations of a new discipline, 263-278. San Francisco: Berrett-Koehler Publishers. 
Epitropaki, O., \& Martin, R. (2005). From ideal to real: A longitudinal study of the role of implicit leadership theories on leader-member exchanges and employee outcomes. Journal of Applied Psychology, 90, 659-676. doi: 10.1037/00219010.90 .4 .659

Feitosa, J., Joseph, D. L., \& Newman, D. A. (2015). Crowdsourcing and personality measurement equivalence: A warning about countries whose primary language is not English. Personality and Individual Differences, 75, 47-52. doi: 10.1016/j.paid.2014.11.017

Feldman, G., Greeson, J., \& Senville, J. (2010). Differential effects of mindful breathing, progressive muscle relaxation, and loving-kindness meditation on decentering and negative reactions to repetitive thoughts. Behavioral Research Therapy, 48(10), 1002-1011. doi: 10.1016/j.brat.2010.06.006

Fletcher, J. K. (2007). Leadership, power, and positive relatinships. In J. E. Dutton \& B. R. Ragins (Eds.), Exploring positive relationships at work: Building a theoretical and research foundation, 347-371. New York: Lawrence Erlbaum Associates.

Fredrickson, B. L., Cohn, M. A., Coffey, K. A., Pek, J., \& Finkel, S. M. (2008). Open hearts build lives: Positive emotions, induced through loving-kindness meditation, build consequential personal resources. Journal of Personality and Social Psychology, 95(5), 1045-1062. doi: 10.1037/a0013262

Gambrel, L. E., \& Keeling, M. L. (2010). Relational aspects of mindfulness: Implications for the practice of marriage and family therapy. Contemporary Family Therapy, 32, 412-426. doi: 10.1007/s10591-010-9129-z 
Gerstner, C. R., \& Day, D. V. (1997). Meta-analytic review of leader-member exchange theory: Correlates and construct issues. Journal of Applied Psychology, 82, 827844. doi: $10.1037 / 0021-9010.82 .6 .827$

Gilbreath, B., \& Benson, P. G. (2004). The contribution of supervisor behavior to employee psychological well-being. Work \& Stress, 18(3), 255-266. doi: $10.1080 / 02678370412331317499$

Giluk, T. L. (2010). Mindfulness-based stress reduction: Facilitating work outcomes through experienced affect and high-quality relationships (Doctoral dissertation). Available at Iowa Research Online.

Glomb, T.M., Duffy, M.K., Bono, J.E., \& Yang, T. (2011). Mindfulness at work. Research in Personnel and Human Resources Management, 30, 115-157. doi: 10.1108/S0742-7301(2011)0000030005

Good, D.J., Lyddy, C.J., Glomb, T.M., Bono, J.E., Brown, K.W., Duffy, M.K., Baer, R.A., ... Lazar, S.W. (2016). Contemplating mindfulness at work: An integrative review. Journal of Management, 42(1), 114-142. doi:

$10.1177 / 0149206315617003$

Graen, G. P. and Uhl-Bien, M. (1995). Relationship-based approach to leadership, development of leader-member exchange (LMX) theory of leadership over 25 years: applying a multilevel multi-domain perspective. Leadership Quarterly, 25, 219-247. doi: 10.1016/1048-9843(95)90036-5 
Harris, K. J., \& Kacmar, K. M. (2006). Too much of a good thing: The curvilinear effect of leader-member exchange on stress. Journal of Social Psychology, 146(1), $65-$ 84. doi: 10.3200/SOCP.146.1.65-84

Hayes, A. F. (2012). PROCESS: A versatile computational tool for observed variable mediation, moderation, and conditional process modeling [White paper]. Retrieved from http://www.afhayes.com/ public/process2012.pdf

Hayes, A. F. (2013). Introduction to Mediation, Moderation, and Conditional Process Analysis: A Regression-Based Approach. New York, NY: The Guilford Press

Hayes, A. F. (2015). An index and test of linear moderated mediation. Multivariate Behavioral Research, 50, 1-22. doi: 10.1080/00273171.2014.962683

Hobfoll, S. E. (1989). Conservation of resources: A new attempt at conceptualizing stress. American Psychologist, 44, 513-524. doi: 10.1037/0003-066X.44.3.513

Holt, S., \& Marques, J. (2012). Empathy in leadership: Appropriate of misplaced? An empirical study on a topic that is asking for attention. Journal of Business Ethics, 105(1), 95-105. doi: 10.1007/s10551-011-0951-5

Homans, G. C. (1958). Social behavior as exchange. American Journal of Sociology, 63, 597-606.

Huang, J. L., Bowling, N. A., Liu, M., \& Li, Y. (2015). Detecting insufficient effort responding with an infrequency scale: Evaluating validity and participant reactions. Journal of Business Psychology, 30, 299-311. doi: 10.1007/s10869014-9357-6 
Huang X., Chan S. C. H., Lam W., \& Nan X. (2010). The joint effect of leader-member exchange and emotional intelligence on burnout and work performance in call centers in China. The International Journal of Human Resource Management, 21, 1124-1144. doi: 10.1080/09585191003783553

Hülsheger, U. R. (2015). Making sure that mindfulness is promoted in organizations in the right way and for the right goals. Industrial and Organizational Psychology, 8(4), 674-679. doi: 10.1017/iop.2015.98

Hülsheger, U. R., Lang, J. W. B., Depenbrock, F., Fehrmann, C., Zijlstra, F. R. H., \& Alberts, H. J. E. M. (2014). The power of presence: The role of mindfulness at work for daily levels and change trajectories of psychological detachment and sleep quality. Journal of Applied Psychology, 99(6), 1113-1128. doi: $10.1037 / \mathrm{a} 0037702$

Hülsheger, U. R., Feinholdt, A., \& Nübold, A. (2015). A low-dose mindfulness intervention and recovery from work: Effects on psychological detachment, sleep quality, and sleep duration. Journal of Occupational and Organizational Psychology, 88, 464-489. doi: 10.1111/joop.12115

Hunter, J., \& Chaskalson, M. (2013). Making the mindful leader: Cultivating skills for facing adaptive challenges. In H. S. Leornard, R. Lewis, A. M. Freedman, \& J. Passmore (Ed.), The Wiley-Blackwell handbook of the psychology of leadership, change, and organizational development (195-219). John Wiley \& Sons, Ltd. 
Ilies, R., Nahrgang, J. D., \& Morgeson, F. P. (2007). Leader-member exchange and citizenship behaviors: A meta-analysis. Journal of Applied Psychology, 92, 269277. doi: 0.1037/0021-9010.92.1.269

Kabat-Zinn, J. (1982). An outpatient program in behavioral medicine for chronic pain patients based on the practice of mindfulness meditation: Theoretical considerations and preliminary results. General Hospital Psychiatry, 4(1), 33-47. doi: 10.1016/0163-8343(82)90026-3

Kabat-Zinn, J. (1990). Full catastrophe living: Using the wisdom of your body and mind to face stress, pain, and illness. New York, NY: Delacorte Press.

Kabat-Zinn, J. (1993). Mindfulness meditation: Health benefits of an ancient Buddhist practice. In D. Goleman \& J. Gurin (Eds.), Mind/body medicine, 259-275. Yonkers, NY: Consumer Reports Books.

Karnes, R. E. (2009). A change in business ethics: The impact on employer-employee relations. Journal of Business Ethics, 87(2), 189-197. doi: 10.1007/s10551-0089878-X

Kelloway, E. K., \& Barling, J. (2010). Leadership development as an intervention in occupational health psychology. Work \& Stress, 24(3), 260-279. doi: $10.1080 / 02678373.2010 .518441$

Klatt, M. D., Buckworth, J., \& Malarkey, W. B. (2009). Effects of low-dose mindfulnessbased stress reduction (MBSR-ld) on working adults. Health Education and Behavior, 36(3), 601-614. doi: 10.1177/1090198108317627 
Krauss, A. (2015). Minding your safety and wellbeing at work: Applied interventions to foster employee mindfulness. Oregon Institute of Occupational Health Sciences Fall 2015 Symposium: Mindfulness and Total Worker Health, Portland, OR.

Krishnakumar, S., \& Robinson, M. D. (2015). Maintaining an even keel: An affectmediated model of mindfulness and hostile work behavior. Emotion, 15(5), 579589. doi: $10.1037 / \mathrm{emo} 0000060$

Mahsud, R., Yukl, G., \& Prussia, G. (2010). Leader empathy, ethical leadership, and relations-oriented behaviors as antecedents of leader-member exchange quality. Journal of Managerial Psychology, 25(6), 561-577. doi: $10.1108 / 02683941011056932$

Martin, R., Guillaume, Y., Thomas, G., Lee, A., \& Epitropaki, O. (2016). Leadermember exchange (LMX) and performance: A meta-analytic review. Personnel Psychology, 69, 67-121. doi: 10.1111/peps.12100

Marques, J. (2013). Understanding the strength of gentleness: Soft-skilled leadership on the rise. Journal of Business Ethics, 116, 163-171. doi: 10.1007/s10551-012$1471-7$

McClelland, D. C. (1951). Trait theory. In D. C. McClelland (Eds.), Personality (201235). New York, NY: William Sloane Association.

Meade, A. W., \& Craig, S. B. (2012). Identifying careless responses in survey data. Psychological Methods, 1-19. doi: 10.1037/a0028085

Michel, A., Bosch, C., \& Rexroth, M. (2014). Mindfulness as a cognitive-emotional segmentation strategy: An intervention promoting work-life balance. Journal of 
Occupational and Organizational Psychology, 87, 733-754. doi:

10.1111/joop. 12072

Peer, E., Vosgerau, J., \& Acquisti, A. (2014). Reputation as a sufficient condition for data quality on Amazon Mechanical Turk. Behavioral Research Methods, 46(4), 1023 1031. doi: 10.3758/s13428-013-0434-y

Preacher, C. J., Rucker, D. D., \& Hayes, A. F. (2007). Addressing moderated mediation hypotheses: Theory, methods, and prescriptions. Multivariate Behavioral Research, 42(1), 185-227. doi: 10.1080/00273170701341316

Quaglia, J. T., Braun, S. E., Freeman, S. P., McDaniel, M. A., \& Brown, K. W. (2016). Meta-analytic evidence for effects of mindfulness training on dimensions of selfreported dispositional mindfulness. Psychological Assessment. Advance Online Publication. doi: 10.1037/pas0000268

Querstret, D., Cropley, M., \& Fife-Schaw, C. (2016). Internet-based instructor-led mindfulness for work-related rumination, fatigue, and sleep: Assessing facets of mindfulness as mechanisms of change. A randomized waitlist control trial. Journal of Occupational Health Psychology. Advance Online Publication. doi: 10.1037/ocp0000028

Reb J., Narayanan, J., \& Chaturvedi, S. (2014). Leading mindfully: two studies of the influence of supervisor trait mindfulness on employee well-being and performance. Mindfulness, 5(1), 36. doi: 10.1007/s12671-012-0144-z 
Reb, J., Narayanan, J., \& Ho, Z. W. (2015). Mindfulness at work: Antecedents and consequences of employee awareness and absent-mindedness. Mindfulness, 6(1), 111. doi: $10.1007 / \mathrm{s} 12671-013-0236-4$

Roche, M., Haar, J. M., \& Luthans, F. (2014). The role of mindfulness and psychological capital on the well-being of leaders. Journal of Occupational Health Psychology, 19(4), 476-489. doi: 10.1037/a0037183

Roeser, R. W., Schonert-Reichl, K. A., Jha, A., Cullen, M., Wallace, L., Wilensky, R., ... Harrison, J. (2013). Mindfulness training and reductions in teacher stress and burnout: Results from two randomized, waitlist-control field trials. Journal of Educational Psychology, 105(3), 787-804. doi: 10.1037/a0032093

Rousseau, D. M., \& Ling, K. (2007). Commentary: Following the resources in positive organizational relationships. In J. E. Dutton \& B. R. Ragins (Eds.), Exploring positive relationships at work: Building a theoretical and research foundation, 373-384. Mahwah, NJ: Lawrence Erlbaum Associates.

Schilling, L. (2010). A historical analysis of the relationship between charisma and the making of great leaders (Doctoral dissertation). Walden University, Minnesota, United States.

Schriesheim, C. A., Neider, L. L., \& Scandura, T. (1998). Delegation and leader-member exchange: Main effects, moderators, and measurement issues. Academy of Management Journal, 41, 298-318. doi: 10.2307/256909

Shapiro, S. L., Astin, J. A., Bishop, S. R., \& Cordova, M. (2005). Mindfulness-based stress reduction for health care professionals: Results from a randomized trial. 
SUPERVISOR MINDFULNESS AND LEADER-MEMBER EXCHANGE

International Journal of Stress Management, 12(2), 164-176. doi: 10.1037/10725245.12 .2 .164

Shapiro, S. L., Carlson, L. E., Astin, J. A., \& Freedman, B. (2006). Mechanisms of mindfulness. Journal of Clinical Psychology, 62(3), 373-386. doi: 10.1002/jclp.20237

Shapiro, S. L., Schwartz, G.E., Bonner, G. (1998). Effects of mindfulness based stress reduction on medical and premedical students. Journal of Behavioral Medicine, 21(6), 581-599. doi: 10.1023/A:1018700829825

Siegel, D. J. (2007). Mindfulness training and neural integration: Differentiation of distinct streams of awareness and the cultivation of well-being. Social, Cognitive, and Affective Neuroscience, 2(4), 259-263. doi: 10.1093/scan/nsm034

Siegel, D. J. (2010). Mindsight: The new science of personal transformation. New York: Bantam.

Skakon, J., Nielsen, K., Borg, V., \& Guzman, J. (2010). Are leaders' well-being, behaviours and style associated with the affective well-being of their employees? A systematic review of three decades of research. Work \& Stress, 24(2), 107-139. doi: $10.1080 / 02678373.2010 .495262$

Sutcliffe, K. M., Vogus, T. J., \& Dane, E. (2016). Mindfulness in organizations: A crosslevel review. Annual Review of Organizational Psychology and Organizational Behavior, 3, 55-81. doi: 10.1146/annurev-orgpsych-041015-062531

Teasdale, J. D., Moore, R. G., Hayhurst, H., Pope, M., Williams, S., \& Segal, Z. V. (2002). Metacognitive awareness and prevention of relapse in depression: 
SUPERVISOR MINDFULNESS AND LEADER-MEMBER EXCHANGE

Empirical evidence. Journal of Consulting and Clinical Psychology, 70, 275-287. doi: 10.1037//0022-006X.70.2.275

Thomas, C. H., \& Lankau, M. J. (2009). Preventing burnout: The effects of LMX and mentoring on socialization, role stress, and burnout. Human Resource Management, 48(3), 417-432. doi: 10.1002/hrm.20288

Wachs, K., \& Cordova, J. V. (2007). Mindful relating: Exploring mindfulness and emotion repertoires in intimate relationships. Journal of Marital and Family Therapy, 33(4), 464-481. doi: 10.1111/j.1752-0606.2007.00032.x

Wenk-Sormaz, H. (2005). Meditation can reduce habitual responding. Alternative Therapies, 2(2), 42-58.

Wolever, R. Q., Bobinet, K. J., McCabe, K., Mackenzie, E. R., Fekete, E., Kusnick, C. A., \& Baime, M. (2012). Effective and viable mind-body stress reduction in the workplace: A randomized controlled trial. Journal of Occupational Health Psychology, 17(2), 246-258. doi: 10.1037/a0027278

Xin, K. R. (2004). Asian American managers: An impression gap?: An investigation of impression management and supervisor-subordinate relationships. The Journal of Applied Behavioral Science, 40, 160-181. doi: 10.1177/0021886304263853

Zhang, J., \& Wu, C. (2014). The influence of dispositional mindfulness on safety behaviors: A dual process perspective. Accident Analysis and Prevention, 70(2014), 24-32. doi: 10.1016/j.aap.2014.03 


\section{Appendix A}

Survey Measures and Response Scales

\section{Current Work Position}

Are you currently supervising employees?

(a) Yes or (b) No.

$$
\text { If yes, how many? }
$$

Age

What is your age?

Fill-in: years

\section{Gender}

What is your gender?

Response Options (Circle one): (a) Male or (b) Female or (c) Other

\section{Marital Status}

What is your marital status?

Response Options (Circle one): (a) Single, never married, (b) Dating someone, (c) Married, (d) Living with a partner, (e) Divorced, or (f) Widowed.

\section{Ethnicity}

What is your ethnicity?

Response Options (Circle all that apply): (a) White (non-Hispanic), (b) Hispanic/Latino, (c) African American, (d) Asian, (e) Native American, (f) Native Alaskan or Pacific Islander, or (g) Other (please specify:

\section{Education Level}

What is the highest level of education you have completed?

Response Options (Circle one): (a) High school/GED, (b) Some college, (c) 2-year college degree (Associate's), (d) 4-year college degree (Bachelor's), (e) Advanced degree (Master's or other), or (f) Other (please specify:

\section{Tenure in current occupation}

How long have you been working in your current supervising position?

Fill-in: years

\section{Hours worked per week}

On average in the past month, how many hours did you work per week?

Fill-in: hours

\section{Frequency of Interaction (McAllister, 1995)}

1. How frequently did you initiate work-related interaction with your employees?

2. How frequently did your employees initiate work-related interaction with you?

3. How frequently did you interact with your employees at work?

4. How frequently did you interact with your employees informally or socially at work? Response options: (1) not at all, (2) once or twice, (3) once or twice a week, (4) once a day, (5) more than once a day. 


\section{Mindful Attention and Awareness Scale (MAAS; Brown \& Ryan, 2003)}

1. I could be experiencing some emotion and not be conscious of it until some time later.

2. I break or spill things because of carelessness, not paying attention, or thinking of something else.

3. I find it difficult to stay focused on what's happening in the present.

4. I tend to walk quickly to get where I'm going without paying attention to what I experience along the way.

5. I tend not to notice feelings of physical tension or discomfort until they really grab my attention.

6. I forget a person's name almost as soon as I've been told it for the first time.

7. It seems I am "running on automatic," without much awareness of what I'm doing.

8. I rush through activities without being really attentive to them.

9. I get so focused on the goal I want to achieve that I lose touch with what I'm doing right now to get there.

10. I do jobs or tasks automatically, without being aware of what I'm doing.

11. I find myself listening to someone with one ear, doing something else at the same time.

12. I drive places on 'automatic pilot' and then wonder why I went there.

13. I find myself preoccupied with the future or the past.

14. I find myself doing things without paying attention.

15. I snack without being aware that I'm eating.

Response options: (1) Almost Always, (2) Very Frequently, (3) Somewhat Frequently, (4)

Somewhat Infrequently, (5) Very Infrequently, (6) Almost Never

\section{Empathic Concern - Interpersonal Reactivity Index (IRI; Davis, 1980)}

1. When I see someone being taken advantage of, I feel kind of protective toward them.

2. When I see someone being treated unfairly, I sometimes don't feel very much pity for them. (-)

3. I often have tender, concerned feelings for people less fortunate than me.

4. I would describe myself as a pretty soft-hearted person.

5. Sometimes I don't feel sorry for other people when they are having problems. (-)

6. Other people's misfortunes do not usually disturb me a great deal. (-)

7. I am often quite touched by things that I see happen.

Response options: (1) Does not describe me, (2) describes me slightly well, (3) describes me moderately well, (4) describes me very well, (5) Describes me extremely well

\section{Perspective Taking (IRI; Davis, 1980)}

1. Before criticizing somebody, I try to imagine how I would feel if I were in their place.

2. If I'm sure I'm right about something, I don't waste much time listening to other people's arguments. (-)

3. I sometimes try to understand my friends better by imagining how things look from their perspective.

4. I believe that there are two sides to every question and try to look at them both.

5. I sometimes find it difficult to see things from the "other guy's" point of view. (-)

6. I try to look at everybody's side of a disagreement before I make a decision.

7. When I'm upset at someone, I usually try to "put myself in his shoes" for a while.

Response options: (1) Does not describe me, (2) describes me slightly well, (3) describes me moderately well, (4) describes me very well, (5) Describes me extremely well 


\section{Response Flexibility - Alternatives Component of the Cognitive Flexibility Inventory (CFI; Dennis \& Vander Wal, 2010)}

1. I am good at "sizing up" situations.

2. I consider multiple options before making a decision.

3. I like to look at difficult situations from many different angles.

4. I seek additional information not immediately available before attributing causes to behavior.

5. I try to think about things from another person's point of view.

6. I am good at putting myself in others' shoes.

7. It is important to look at difficult situations from many different angles.

8. When in difficult situations, I consider multiple options before deciding how to behave.

9. I often look at a situation from different viewpoints.

10. I consider all the available facts and information when attributing causes to behavior.

11. When I encounter difficult situations, I stop and try to think of several ways to resolve it.

12. I can think of more than one way to resolve a difficult situation I'm confronted with.

13. I consider multiple options before responding to difficult situations.

Response options: (1) Strongly disagree, (2) Somewhat disagree, (3) Neither agree nor disagree, (4) Somewhat agree, (5) Strongly agree

\section{Leader-Member Exchange (LMX-7; Graen \& Uhl-Bien, 1995)}

1. Do your employees know where they stand with you? (1) Rarely, (2) Occasionally, (3) Sometimes, (4) Fairly Often, (5) Very Often

2. How well do you understand your employees' job problems and needs? (1) Not a bit, (2) A Little, (3) A Fair Amount, (4) Quite a Bit, (5) A Great Deal

3. How well do you recognize your employees' potentials? (1) Not at All, (2) A Little, (3) Moderately, (4) Mostly, (5) Fully

4. Regardless of how much formal authority you have built into your position, what are the chances that you would use you power to help your employees solve problems in their work? (1) None, (2) Small, (3) Moderate, (4) High, (5) Very High

5. Again, regardless of the amount of formal authority that you have, what are the chances that you would "bail out," an employee at your own expense?

(1) None, (2) Small, (3) Moderate, (4) High, (5) Very High

6. My employees have enough confidence in me that they would defend and justify my decision if I were not present to do so.

(1) Strongly Disagree, (2) Disagree, (3) Neutral, (4) Agree, (5) Strongly Agree

7. How would you characterize your working relationship with your employees?

(1) Extremely Ineffective, (2) Worse Than Average, (3) Average, (4) Better than Average,

(5) Extremely Effective

\section{Workload (Spector \& Jex, 1998)}

1. How often did your job require you to work very fast?

2. How often did your job require you to work very hard?

3. How often did your job leave you with little time to get things done?

4. How often was there a great deal to be done?

5. How often did you have to do more work than you could do well?

Response options: (1) very rarely to never, (2) rarely, (3) occasionally, (4) frequently, (5) very frequently 


\section{Appendix B}

Attention Check Items

1. Please select "almost never" in response to this question.

(1) Almost Always, (2) Very Frequently, (3) Somewhat Frequently, (4) Somewhat Infrequently, (5) Very Infrequently, (6) Almost Never

2. What does two plus 3 equal to?

(1) Seven, (2) Three, (3) Five, (4) Four

3. I am currently using an electronic device to take this survey.

(1) Strongly disagree, (2) Somewhat disagree, (3) Neither agree nor disagree, (4)

Somewhat agree, (5) Strongly agree

4. I have been to every country in the world.

(1) Strongly disagree, (2) Somewhat disagree, (3) Neither agree nor disagree, (4)

Somewhat agree, (5) Strongly agree

5. I have never used a computer.

(1) Strongly disagree, (2) Somewhat disagree, (3) Neither agree nor disagree, (4)

Somewhat agree, (5) Strongly agree 